Portland State University

PDXScholar

1990

\title{
Intergenerational relations in the workplace : older women and their younger women co-workers
}

Julie Suzanne Reynolds

Portland State University

Follow this and additional works at: https://pdxscholar.library.pdx.edu/open_access_etds

Part of the Psychology Commons

Let us know how access to this document benefits you.

\section{Recommended Citation}

Reynolds, Julie Suzanne, "Intergenerational relations in the workplace : older women and their younger women co-workers" (1990). Dissertations and Theses. Paper 4148.

https://doi.org/10.15760/etd.6032

This Thesis is brought to you for free and open access. It has been accepted for inclusion in Dissertations and Theses by an authorized administrator of PDXScholar. Please contact us if we can make this document more accessible: pdxscholar@pdx.edu. 
AN ABSTRACT OF THE THESIS of Julie Suzanne Reynolds for the Master of Science in Psychology presented March 16, 1990.

Title: Intergenerational Relations in the Workplace: Older Women and Their Younger Women Co-Workers

APPROVED BY MEMBERS OF THE THESIS COMMITTEE:

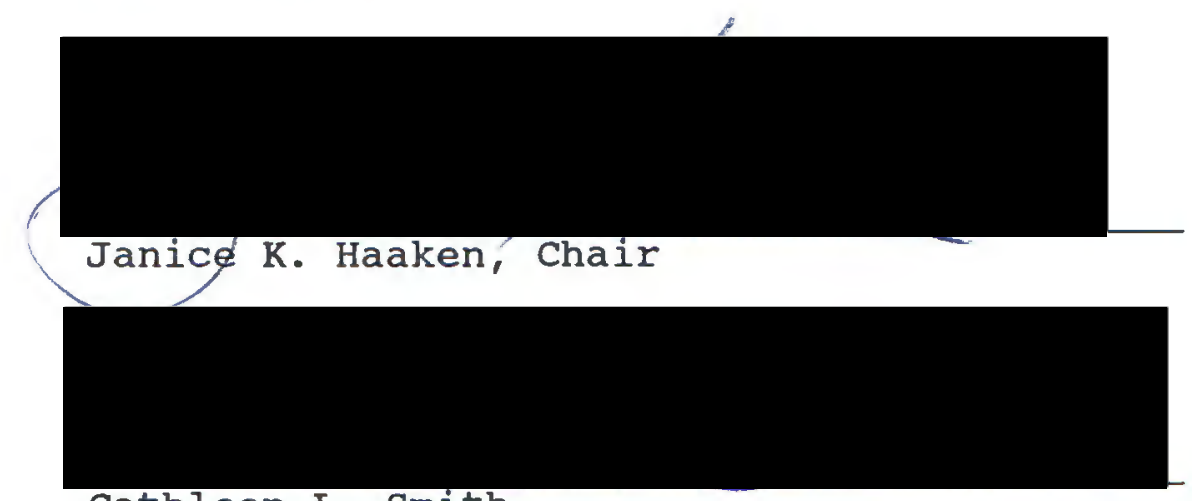

Cathleen L. Smith

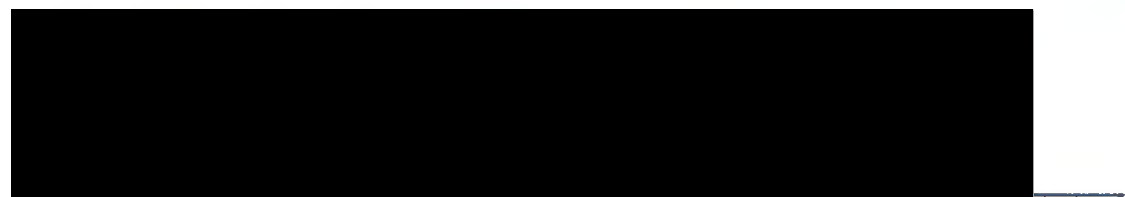

Thomas A. Kindermann

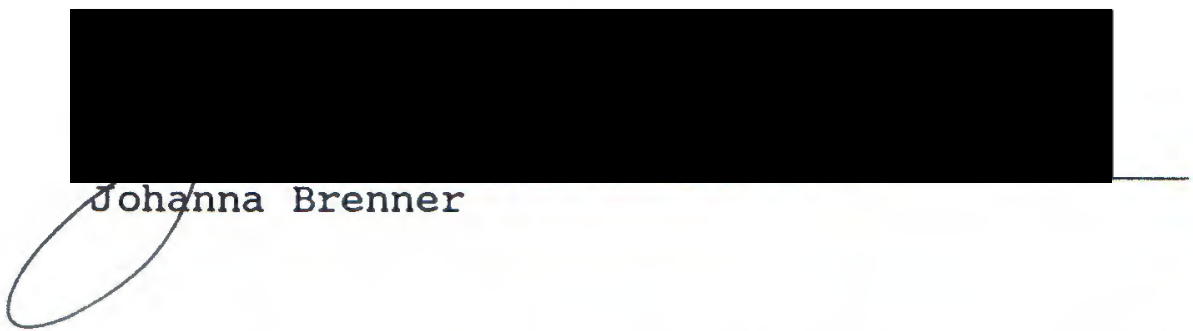

Women aged 55 and older have been participating actively in the American work force and recently have been drawing increased attention from researchers in the social sciences (Ashbaugh \& Fay, 1987). This study examines the nature of 
service work performed by older part-time women workers and their younger women co-workers, and the relationship between the two generations in the workplace.

The following research questions guided this exploratory study: Do the older women workers and their younger women co-workers report that there have been changes in the co-workers' work since the older women began working at the job site? What do the older women workers and their younger women co-workers perceive to be the emotional quality of their intergenerational interaction in the workplace? If the co-workers report that the way their work is performed in the setting has changed since the older women began working, is the intergenerational relationship influenced by the perceived change in the distribution of work?

Semi-structured interviews were conducted with 32 older women workers (age range $=55-83$ ) and 32 younger women coworkers (age range $=22-58$ ) designated by the older women. The older women workers were employed half-time by the Foster Grandparents Program (FGP) or the Senior community Service Employment Program (SCSEP). They worked at job sites with their younger women co-workers, who were employed full-time.

Content analysis of interview data produced 12 codes for the older women workers, 17 codes for the younger women 
co-workers, and 7 codes for both groups which reached the reliability criterion of 60 percent agreement. Kappas for 21 interviews checked for reliability ranged from .78 to 1.0 $(\underline{m}=.87)$.

Rank order correlation (Spearman's rho) was significant for both the older women workers $(\underline{p}<.02)$ and the younger co-workers $(\underline{p}<.01)$, showing that program differences in the rank ordering of codes mentioned existed between the FGP and SCSEP work settings for both generations.

The perceived impact of the older women's entry into the workplace was illustrated by the results of a binomial test of the hypothesis that matched pairs of older women workers and younger co-workers would agree above chance that the older women had lessened work pressure on their coworkers (IMPPRESS) $(\underline{p}<.005)$.

Codes bearing on intergenerational relations included the older women workers' awareness that they were being used as cheap labor (CHEAP) $\left(\underline{x}^{2}=4.66, \underline{p}=.031\right)$ in SCSEP, which was complemented by the younger co-workers' recognition that the older women were being paid less than others at the work site (PAYREL) $\left(\underline{x}^{2}=10.78, \underline{p}=.001\right)$. Within the Foster Grandparents Program, the older women workers' statements that they had taken over the emotional component of labor, freeing their younger co-workers for other tasks (IMPEMOT) $\left(\underline{x}^{2}=13.85, \underline{p}<.001\right)$ was acknowledged by those co-workers 
in their mentions of how the older women took on nurturing tasks (HELPNURT) $\left(\underline{x}^{2}=21.21, \underline{p}<.001\right)$.

This study of older women workers and their younger women co-workers demonstrated that there was a perceived impact of the older women's entry into the work force on the work of their younger co-workers. Relations between the two generations were seen to be cordial, with both negative and positive aspects mentioned by the co-workers. No significant relationship was found between the perceived impact of the older women's work on that of their younger co-workers and intergenerational relationships in the workplace. 
INTERGENERATIONAL RELATIONS

IN THE WORKPLACE:

OLDER WOMEN AND THEIR YOUNGER WOMEN CO-WORKERS

by

JULIE SUZANNE REYNOLDS

A thesis submitted in partial fulfillment of the requirements for the degree of

\author{
MASTER OF SCIENCE \\ in \\ PSYCHOLOGY
}

Portland State University

1990 
TO THE OFFICE OF GRADUATE STUDIES:

The members of the committee approve the thesis of Julie Suzanne Reynolds presented March 16, 1990.
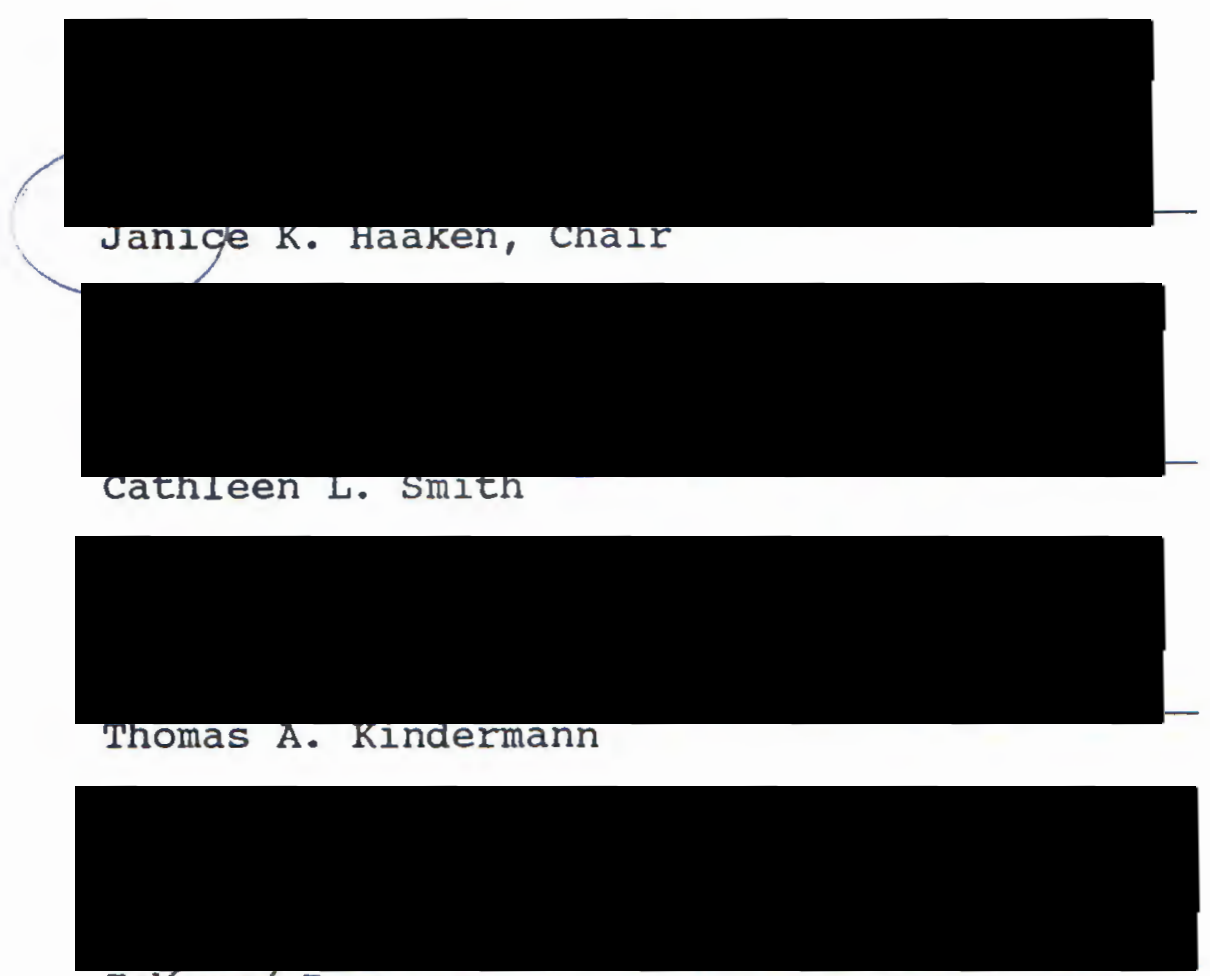

Johanna Brenner

APPROVED:

Cord B. Sengstake, Chair, Department of Psychology 


\section{ACKNOWLEDGEMENTS}

Many thanks to the following persons for helping me complete this thesis project:

To my advisor and thesis chair, Dr. Janice K. Haaken, and to my thesis committee, Dr. Cathleen L. Smith, Dr. David Cressler (deceased), Dr. Thomas Kindermann, and Dr. Johanna Brenner, for their time and helpful suggestions.

To Teresa Dobles, Christine Nelson, Jill Harris Strasser and Connie Whipple, for serving as interviewers.

To Carolyn wright, for transcribing the interview tapes.

To the student assistants for the study, Lance Duncan, Ramona Gonzalez, Julie Lieberman, Pam Mabry, Lorrie Riat, Jeannie Van Dooremolen, and Tracy Wood, for their hard work.

To the older women workers from the Foster Grandparent Program (FGP) and the Senior Community Service Employment Program (SCSEP) and to their younger women co-workers, for serving as subjects for this study.

To Linda Pelleg-Carson, Director of the Senior Community Service Employment Program (SCSEP), and Frank Hales, Director of the Foster Grandparent Program (FGP), for allowing recruitment of their program members.

To Dr. Nancy Perrin for statistical advice. 
To Laura Borders and Pam Mabry, for their sustaining friendship.

To my husband, Roland Kwee. 
TABLE OF CONTENTS

PAGE

ACKNOWLEDGEMENTS. . . . . . . . . . . . . . . . . iii

LIST OF TABLES. . . . . . . . . . . . . . . . . . viii

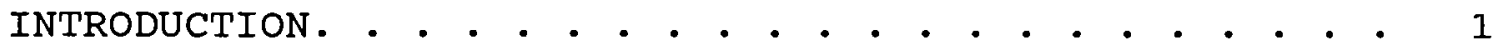

Intergenerational Relations Between older

Women Workers and Younger Women Co-Workers. . 3

Perspectives on Part-Time Work . . . . . . . . 6

Perspectives on Service Work . . . . . . . . 8 METHOD. • . . . . . . . . . . . . . . . . . 15

subjects . . . . . . . . . . . . 15

Older Women Workers $(\underline{\mathrm{n}}=32)$

Younger Women Co-Workers $(\mathrm{n}=32)$

Settings . . . . . . . . . . . . . . . 20

Foster Grandparent Program (FGP)

Senior Community Service Employment Program (SCSEP)

work Sites

Interviewers . . . . . . . . . . . . . . 23

Instruments. . . . . . . . . . . . . . 23

Interview with older Woman Worker

Interview with Younger Woman Co-Worker

Interview Procedure. . . . . . . . . . . . 25

Content Analysis . . . . . . . . . . . . 27

Coding Procedure . . . . . . . . . . . . 28 
PAGE

Reliability of Coders (Cohen's kappa)

Reliability of Coders (Percent Agreement)

Coding system. . . . . . . . . . . . . . . 34

Codes for the Older Women Workers

Good Feelings

Bad Feelings

Conflict

Sources of Satisfaction

Impact

Codes for the Younger Women Co-Workers

Help

Hinder

Positive

Negative

conflict

Codes for Both Older Women Workers and

Younger Women Co-Workers

Conflict

Inequities

Impact

RESULTS .

Impact of the Older Women Workers on the Work

of the Younger Women Co-Workers . . . . . . 42

Program Differences (FGP and SCSEP). . . . . . . 44

Intergenerational Relationships. . . . . . . 45

Perceptions of the Older Women Workers

Perceptions of the Younger Women Co-Workers

Perceptions of the Older Women Workers and

Younger Women Co-Workers

Impact of Perceived Changes in the Co-Workers'

Work on Intergenerational Relationships

in the Workplace. . . . . . . . . . . . 54

DISCUSSION. • . . • . . • . • . • . . . . 57

Impact of the Older Womens' Work . . . . . . . 57 
Program Differences (FGP and SCSEP). . . . . . 59

Older Women Workers

Younger Women Co-Workers

Intergenerational Differences (Older Women Workers and Younger Women Co-Workers) . . . . . . 62

Intergenerational Relationships. . . . . . . 63

Impact of Perceived Change in the Co-workers'

Work on Intergenerational Relationships

in the Workplace. . . . . . . . . . . 64

Limitations of the study . . . . . . . . . 65

Issues of Reliability and Validity . . . . . . 67

Validity of the Subjects' Responses

Reliability of the Interviewers and coders

Reliability and Validity of the coding system

Reliability of the Codes

Conclusions. . . . . . . . . . . . . . 74

Suggestions for Future Research. . . . . . . 73

REFERENCES. . . . . . . . . . . . . . . . 76

APPENDICES

A OLDER WOMAN WORKER INTERVIEW FORM . . . . . . 81

B YOUNGER WOMAN CO-WORKER INTERVIEW FORM. . . . 90

C CODEBOOK FOR OLDER WOMAN WORKER . . . . . . . 94

D CODEBOOK FOR YOUNGER WOMAN CO-WORKER. . . . 112

E CODES NOT REACHING RELIABILITY CRITERION. • . 128

F CONSENT FORMS . . . . . . . . . . . . . . 133 


\section{LIST OF TABLES}

TABLE

PAGE

I Characteristics of Older Women Workers and Younger Women Co-Workers . . . . . . 17

II Work-Related Characteristics of Older Women Workers. . . . . . . . . . . 19

III Work-Related Characteristics of Younger Women Co-Workers . . . . . . . . . . 21

IV Reliability: Percent Agreement of Coders for Each Code (Older Women Workers). . . 31

V Reliability: Percent Agreement of Coders for Each Code (Younger Women Co-Workers) . 32

VI Reliability: Percent Agreement of Coders for Each Code [Older Women Workers (OWW) and Younger Women Co-Workers (COW)]. . . 33

VII Percentage of Older Women Workers (OWW) and Younger Women Co-Workers (COW) Mentioning "Impact" Codes. . . . . . . . . 43

VIII Percentage of Older Women Workers

Mentioning "Intergenerational

Relations" Codes . . . . . . . . . . 47

IX Percentage of Younger Women Co-Workers

Mentioning "Intergenerational

Relations" Codes . . . . . . . . . 51

$\mathrm{X}$ Percentage of Older Women Workers (OWW)

and Younger Women Co-Workers (COW)

Mentioning "Intergenerational

Relations" codes . . . . . . . . . 54

XI Percentage of Older Women Workers (OWW)

and Younger Women Co-Workers (COW)

Mentioning Codes Not Reaching

60 Percent Agreement . . . . . . . . . .129 
XII Reliability: Percent Agreement of Coders for Codes Not Reaching 60 Percent Agreement (Older Women Workers and Younger Women Co-Workers). . . . . . . .131 


\section{INTRODUCTION}

Women aged 55 and older have been participating actively in the American work force and recently have been drawing increased attention from researchers in the social sciences (Ashbaugh \& Fay, 1987). But older working women have rarely been studied in their own right. Previous studies of women and work have focused on younger women and the interface between work and family (Nieva, 1985; Voydanoff, 1987).

older male workers have been the subject of studies which emphasized retirement and post-retirement work (Fleisher, 1981; McConnell, 1981), options that may have more relevance for men than for women, who are less likely than men to have occupied full-time positions where they would qualify for pension coverage (Herz, 1988; Shaw, 1985).

studies of intergenerational relations in the workplace have focused on relations between older adults and children in childcare settings (Saltz, 1971), rather than on relations between adult co-workers.

This study examines the nature of service work performed by older part-time women workers and their younger women co-workers, and the relationship between the two generations in the workplace. This focus is supported by 
the increasing numbers of older women in the workforce (Stentzel, 1987), the stated preference of older persons for part-time work (Usher, 1981), the increasing number of jobs available in the service sector where most part-time work is found (Deuterman \& Brown, 1978), and the concentration of women in low-paid service jobs (Kahne, 1985).

The number of elderly persons in the United States is expected to rise at least through the year 2050 (Soldo \& Agree, 1988), and older women are likely to become a larger proportion of the population in the future (Marshall \& Paulin, 1987). When older women experience divorce and widowhood, they may be left dependent on their own resources to earn a living. As a group, older women are known to be economically vulnerable; Harris (1981) reported that 80 percent of Caucasian women over the age of 65 had incomes of less than $\$ 5000$ per year, and Black and Hispanic women fared even worse.

older women may also have non-economic reasons for seeking employment. The same factors which can lead to jobseeking for financial reasons---divorce and widowhood, for example---may also lead to an increased need for new interests and activities (Shaw \& Shaw, 1987). Older respondents cited the opportunity to help others, to feel useful, and to get out of the house, when asked to give reasons why they participated in a voluntary government- 
sponsored program to help children with special needs (ACTION, 1984).

A variety of labor market factors may influence an older women's ability to find work in the years to come. olson (1982) foresees a labor shortage caused by a declining American birthrate, which could serve to draw older persons into the work force. But Marshall and Paulin (1987) cast doubt on this position by including projections for legal and illegal immigration which could cause an influx of younger persons into the labor market.

Discrimination and the existence of ageist stereotyping can be barriers to the employment of older women. Discrimination against older workers is active, despite the federal and state laws which prohibit it. Although many sources document the mental and physical capabilities of older workers (Jacobson, 1979; Sparrow, 1986; Stagner, 1985), a recent survey of 400 companies revealed that employers still have questions about whether older persons can adapt to new technology (Stephens, 1989).

INTERGENERATIONAL RELATIONS BETWEEN OLDER WOMEN WORKERS AND YOUNGER WOMEN CO-WORKERS

The social context in which work takes place may influence the nature of contact between generations. Intergenerational relations established between older women 
workers and their younger women co-workers in the workplace have the potential for both support and conflict.

From a psychosocial point of view, work can be seen as representing an opportunity for people to come together as a social group to engage in a common task (Veroff, Douvan \& Kulka, 1981). There is evidence that cordial relationships at work are a priority for most workers. Using survey data from a nationwide representative sample of adults, veroff, Douvan, and Kulka (1981) suggest that female workers, more than males, are concerned with getting along with their coworkers. The study reported that, for women, relationships with people were a major source of satisfaction at work.

Among factors which affect work-related sources of social support, an unequal or competitive status between workers hinders supportive relationships (House, 1981). Veroff et al. (1981) speculated that younger co-workers who have better education and training might be seen as a competitive threat to older workers. On the other hand, it is also possible that older persons may be viewed as competition by their younger co-workers.

Intergenerational competition has been observed in a setting outside the workplace. Auerbach and Levenson (1977) measured attitudes towards the elderly held by young college students (age 18-22) who were part of a mixed group of young and old ( 65 years or older) college students. The younger 
students' attitudes were measured at the beginning and end of a semester. At the second time of measurement, the attitudes of the younger students who were in contact with older students were significantly more negative towards the elderly than those of a control group that had not been in contact with older students. The older students were seen as "unfair competition" by the younger students because they were willing to expend more energy on assignments and to seek closer contact with the course instructors.

Besides the perception of competition, age stereotypes held by younger women co-workers also may influence relations with the older women with whom they work. The existence of age stereotyping is well-documented in work settings (Stentzel, 1987). In a study of discrimination among employees, Haefner (1977) found that younger employees preferred to work with younger co-workers, but older employees had no age preference. Female workers preferred to work with other females and with highly competent individuals. These findings suggest that the perceived competence of the older woman may affect her acceptance by her younger co-workers.

Muchinsky (1978) found that employees over age 50 were not as happy with their co-workers as were employees in other age groups. He speculated that for established workers, this might be due to a loss of old colleagues to 
retirement and death and a dissatisfaction with the younger co-workers who remained. An alternate interpretation could attribute the older workers' dissatisfaction to the existence of ageist beliefs held by younger co-workers, possibly leading to discriminatory behavior. The older workers in Muchinsky's study had been present in the organization prior to the younger workers. However, in organizations where older persons are the more recently hired workers, Muchinsky's speculation concerning the loss of older colleagues should not apply.

\section{PERSPECTIVES ON PART-TIME WORK}

The fact that older persons are often employed parttime by their own choice may be a major determinant of intergenerational relations in the workplace. Both women and men in older age groups who want or need to work prefer to work part-time (Fleisher, 1981; Root, 1981; Usher, 1981). A survey by Lou Harris and Associates (1981) reported that 79 percent of persons aged 55-69 wanted at least part-time work after retirement.

Part-time work has been an especially attractive option for women, many of whom also may have the primary responsibility for performing daily work in their own households (Eccles \& Hoffman, 1984). It is not surprising that a higher proportion of the female workforce (30 
percent) than the male workforce (12 percent) is employed part-time (U.S. Department of Labor, 1984). In 1986, among persons over the age of 65 who were working, 47 percent of men and 59 percent of women held part-time jobs (soldo \& Agree, 1988).

A recent poll of corporate executives showed an increased interest in hiring older persons to perform parttime work (Crawford, 1990). Although part-time work offers older persons an opportunity to earn money while maintaining social interaction, it can also mean less job security, below-average pay rates, and lack of benefits (including health insurance), compared to full-time work. Women may end up working part-time because they have no other option (Crawford, 1990).

Full-time workers also may be adversely affected by a part-time labor force. Curran (1984) has reported that employers have used part-time workers as a cost-cutting measure to replace full-time workers who would be entitled to fringe benefits like health insurance and who would demand regular work hours, regular pay increases, and job security. Labor unions have historically fought against the hiring of part-time workers to preserve full-time positions for younger workers coming into the labor force (Kaplan, 1981). 
The public image of part-time workers also may have a negative aspect, according to a study of part-time employees and gender stereotypes conducted by Eagly and steffen (1986). Data gathered in this study indicated that women employed part-time were assumed to be adding their part-time work role to the role of homemaker. Despite the assumption of an added work role, these women were considered to have less concern for others which is stereotypically associated with full-time housewives, as well as less active concern for mastering tasks which is an attribute associated with full-time employees. In this study, women who worked parttime were perceived as less competent than full-time workers in fulfilling the tasks of either domestic or paid work.

\section{PERSPECTIVES ON SERVICE WORK}

Most part-time jobs are found in service work, which can be defined as employment in which services, rather than produced goods, are exchanged for wages. Deuterman and Brown (1978) have identified the service sector as an area of rapidly expanding employment. In 1987, almost two-thirds of working women aged 55 and older were employed in service work (Herz, 1988). More jobs will become available in this area as it increases in scope, while jobs will continue to decrease in the industrial sector of the economy, where 
technological advances have reduced the need for labor (Best, 1979).

In contrast to the way industry uses technology to restructure work, service work can be restructured by bringing in a new group of workers. With regard to service work, Braverman (1971) describes an historical trend within capitalism toward breaking down the work performed by one person into smaller components over a period of time in a process called "de-skilling." Each of the components of the original job can be performed by a less-skilled worker for less pay. De-skilling also reduces worker control over the production process by reducing the scope of the work.

Several authors have used this argument (Braverman, 1971; Feldberg \& Glenn, 1983) to provide a perspective from which to look at service work performed by older women as it affects the work of others in the organization. Bringing low-paid, part-time workers into an organization may have a "de-skilling" effect on the way existing service work is performed. To the extent that older women workers may move into work situations where they form the bottom rank of the least-skilled workers, they may find themselves doing work which once was part of a more complex, highly-skilled job. The occupant of the original job may find that she is now performing different work, which may also be subject to a "de-skilling" process. 
One result of employing part-time older women as workers might be to downgrade the job of a regular worker by taking away work previously performed for a higher wage by that worker, and having it performed for lower wages by less-skilled workers. In this case, the low-paid, part-time workers might be perceived negatively, as a threat to the jobs of other workers (Braverman, 1971).

Another result of bringing in low-paid part-time workers might be to upgrade the work done by the regular staff. From this perspective, the part-time worker could be seen as preventing a regular worker from experiencing work overload, or giving that worker more freedom to perform different or more complex tasks (Schindler-Rainman \& Lippit, 1971). This would be viewed positively by the regular worker.

A third possible result of hiring low-paid, part-time workers might be to have no impact at all on the existing work if these workers were hired to perform newly created work.

Service work jobs are generally low-status, low-paid, and offer little chance for the specialization and advancement which lead to higher income (Graham, 1983; Kahne, 1985). They have been characterized as containing many of the elements of the roles of mother and wife (Nieva, 1985), which are past or present roles for most women. The 
skills gained in a lifetime of unpaid service work in the home are especially likely to point older women toward paid service work, where they can derive some financial benefit from their experience.

From a feminist perspective, Hochschild (1983) argues that women's socialization to helping others is a kind of preparatory training for the nurturant aspects of service work. Before the Industrial Revolution, most work done by either sex took place in or near the home. After industrialization, work began to be performed outside the home for wages. Because women were tied to raising children, they were the ones who remained in the domestic setting, occasionally working outside the home to supplement the family income. Domestic work, performed in the home as unpaid labor, has come to be seen as less valuable and less important than wage work, although both contribute to the economic status of the family and the nation (Voydanoff, 1987).

Part of domestic work involves "managing" feelings of oneself and others to make sure social interactions run smoothly. Women are expected to adapt their behavior to the needs of others. Hochschild (1983) argues that women's relative lack of access to money and power is reflected in the "emotion work" done in the home in exchange for economic support from the male partner. When women enter the paid 
labor market, they take with them skill in the management of emotions, which is assumed to be an intrinsic feminine trait, rather than an acquired skill. Because women have not trained outside the home to gain their skill in "emotion management," their abilities in this area are devalued.

Service work requires a component of this type of emotion management in face-to-face interactions with clients and customers. Because emotion work is seen as "natural" for women, however, it is not considered "real" work (Nieva, 1985). This line of reasoning may lead to lower wages for women who perform service work.

Furthermore, since managing emotions is felt to be rewarding in itself, employers justify lower pay for women in service jobs because the emotional rewards of giving care are thought to compensate for the low pay (Hochschild, 1983) .

Braverman's (1971) and Hochschild's (1983) arguments can be combined to provide a perspective on the way parttime older women workers might affect the work done in an organization: There is an historical trend of breaking skilled jobs into simpler jobs which may be performed with fewer skills and for lower pay than the original work (Braverman, 1971). In the domain of service work, such jobs may be held by women because they appear to be an extension of emotional work done in the home (Hochschild, 1983). When 
older women workers are brought into an organization to perform part-time service work for lower pay than their younger co-workers, they may be viewed either negatively (as taking away work previously performed by the younger coworkers), or positively (as freeing up the younger coworkers to perform more "important," or socially-valued, work). This context may influence both how the younger women co-workers view the contribution of the older women workers, and how intergenerational relationships are formed. The focus of this study was on the nature of service work performed by older and younger women as co-workers, and on the quality of their intergenerational relationships in the workplace. Because no research had been done previously in this area, this study constituted an initial exploration of unfamiliar territory.

The following research questions guided this exploratory study: Do the older women workers and their younger women co-workers report that there have been changes in the co-workers' work since the older women began working at the job site? What do the older women workers and their younger women co-workers perceive to be the emotional quality of their intergenerational interaction in the workplace? If the co-workers report that the way their work is performed in the setting has changed since the older women began working, is the intergenerational relationship 
influenced by the perceived change in the distribution of work? 
METHOD

SUBJECTS

\section{older Women workers $(n=32)$}

Women from two Portland-area government-sponsored programs, the Foster Grandparent Program (FGP) $(n=16)$ and the Senior Community Service Employment Program (SCSEP) ( $n=$ 16), who volunteered for participation in the study were interviewed. Each woman worked with a female co-worker who was at least 16 years younger than the older woman. In addition, each woman had an adult son or daughter living in the Portland area who consented to be interviewed in for a larger research project, of which this study was a part, encompassing intergenerational relations in the family and the workplace.

The older women had a median age of 66 years (range = 55-83 years). There was a significant difference between the average ages of the women in the Foster Grandparent Program and the senior Community Service Employment Program $(\underline{t}=8.50, \underline{d f}=30, \underline{p}<.001)$. Women in FGP had a median age of 72 years (range $=65-83$ years); women in SCSEP had a median age of 61 years (range $=55-69$ years) 
Half of the older women workers had completed at least a high school education (median length of education $=12$ years). Four of those who had not finished high school had obtained a Graduate Equivalency Degree (GED) .

Thirty-one (97\%) of the older women were caucasian, one (3\%) was Black.

None of the older women was currently married, although all had been married previously. Seventeen (53\%) of the women were separated or divorced and 15 (46\%) were widowed. The husbands of 14 (44\%) of the older women had been bluecollar or skilled workers, 6 (19\%) had been self-employed or owned a small business, and 5 (16\%) had been managers or were professionally trained. Data were not available for 7 $(22 \%)$ of the older women.

Demographic data for the older women workers are given in Table I.

Ten $(31 \%)$ of the older women workers named as preparation for their current jobs paid social service work, 9 (28\%) of older women workers named paid clerical, technical or business work, $8(25 \%)$ named experience in the home, 3 (9\%) named volunteer work, and 3 (9\%) named no work experience.

The prior work roles with which the women identified most strongly were paid work for 11 ( $34 \%)$, family for 1 (3\%), and both work and family for 7 (22\%). Thirteen (41\%) 
TABLE I

CHARACTERISTICS OF OLDER WOMEN WORKERS

AND YOUNGER WOMEN CO-WORKERS $(\mathrm{N}=64)$

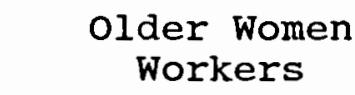

Total FGP SCSEP

$(n=32) \quad(n=16) \quad(n=16)$
Younger Women workers

\section{Age (years)}

$\begin{array}{lcccccc}\text { Range } & 55-83 & 65-83 & 55-69 & 22-58 & 22-58 & 22-42 \\ \text { Median } & 66 & 72 & 61 & 36 & 36 & 37\end{array}$

Education (years)

$\begin{array}{lcccccc}\text { Range } & 4-16 & 5-16 & 8-16 & 11-21 & 12-19 & 11-20 \\ \text { Median } & 12 & 11 & 12 & 16 & 16 & 15\end{array}$

$\underline{\text { Race }}$

$\begin{array}{lcccccc}\text { Caucasian } & 31 & 15 & 16 & 27 & 12 & 15 \\ \text { Black } & 1 & 1 & 0 & 4 & 3 & 1 \\ \text { Asian } & 0 & 0 & 0 & 1 & 1 & 0\end{array}$

Marital status

$\begin{array}{lcccccc}\text { Married } & 0 & 0 & 0 & 16 & 9 & 7 \\ \text { Separated/ } & & & & & & \\ \quad \text { Divorced } & 17 & 6 & 11 & 9 & 3 & 6 \\ \text { Widowed } & 15 & 10 & 5 & 0 & 0 & 0 \\ \text { Never married } & 0 & 0 & 0 & 7 & 4 & 3\end{array}$

Husband's occupation

Blue-collar/

Skilled worker 14

Self-employed/

Small business 6

86

4

1

3

Professional/

Managerial

15

1

1

0

Not applicable

5
$\mathbf{0}$
7

2
0
5

3

13

8

5

Not available

5

0

7

4

3

5 
of the women described their work experience very briefly or without evaluative comments.

Nineteen ( $59 \%$ ) of the older women reported paid work histories in clerical, technical, or business settings, 9 $(28 \%)$ in social service work, 1 (3\%) in self-employed positions or family businesses, and $3(9 \%)$ in some other setting.

Work-related characteristics of the older women are given in Table II. These characteristics include work preparation, work identification, and work history.

Younger women co-workers $(n=32)$

Each older woman worker designated the one younger woman co-worker in a non-managerial position with whom she had the most contact at work. Demographic data for the younger women co-workers are given in Table I.

The co-workers had a median age of 36 years (range = 22-58 years). Each younger woman was at least 16 years younger than the older woman with whom she worked, with a median age difference of 31 years (range $=16-53$ years)

On average, co-workers had completed four years of college, and several had earned masters degrees.

Twenty-seven (84\%) were Caucasian, 4 (13\%) were Black, and 1 (3\%) was Asian.

Sixteen (50\%) of the co-workers were married, 9 (28\%) were separated or divorced, and 7 (21\%) were not married. 
TABLE II

WORK-RELATED CHARACTERISTICS OF OLDER WOMEN WORKERS

$\begin{array}{ccc}\text { Total } & \text { FGP } & \text { SCSEP } \\ (n=32) & (n=16) & (n=16)\end{array}$

Work preparation ${ }^{1}$

Social service

Clerical/Technical/Business

10

9

Home

Volunteer

None

Not available

8

3

3

1

$\begin{array}{ll}3 & 7 \\ 1 & 8 \\ 8 & 0 \\ 3 & 0 \\ 3 & 0 \\ 0 & 1\end{array}$

Work identification

Past work

Both family and work

Family

Brief or without comment
11

7

1

13
7
8
0
0
0
1

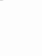


months). Co-workers in FGP had been in their current jobs for a median time of 24 months (range $=4-144$ months), and co-workers in SCSEP had been in their current jobs for a median time of 36 months (range $=1-78$ months).

Twenty (63\%) of the work sites were unionized, and 17 (47\%) of the co-workers belonged to a union or professional association. Whether or not they were members, 10 (31\%) of the co-workers supported union principles, $3(9 \%)$ saw unions as unnecessary or interfering, 5 (16\%) expressed both positive and negative sentiments, and 14 ( $44 \%$ ) perceived unions as irrelevant or knew nothing about them.

Work-related characteristics of the younger women coworkers regarding their union membership and attitudes towards labor unions are given in Table III.

\section{SETTINGS}

Both FGP and SCSEP are government-sponsored programs which provide work in the area of social services for older persons who meet the requirements of minimum age, maximum income from other sources, and part-time employment (i.e., 20 hours per week). Income levels and pay rates stipulated by the programs and reported below were in effect during the time data were collected for this study. 
TABLE III

WORK-RELATED CHARACTERISTICS OF YOUNGER WOMEN CO-WORKERS $\underset{(n=32)}{\text { Total }}$ FGP
$(n=16)$ SCSEP $(n=16)$

Union membership ${ }^{1}$

Member

Non-member

Union attitude

Positive

Negative

Ambivalent

Indifferent
15

17

10

3

5

14
7

9
8

8

Note ${ }^{1}$ : Ten FGP and 10 SCSEP work sites had a union or professional association which the younger women coworkers could join.

\section{Foster Grandparent Program (FGP)}

FGP is one of three national programs mandated by the older Americans Act of 1965. It provides orientation and inservice training to its "volunteers," who perform their work in hospitals, schools, group homes, day care centers, etc. To qualify for participation in FGP, a person must be aged 60 or older and have an income of less than $\$ 6000$ if single, or $\$ 7200$ if married. The aim of FGP is to benefit both children with emotional and physical needs and older "volunteers" with economic and social needs by encouraging "quasi-family" relationships between the "volunteers" and the children (ACTION, 1984; Saltz, 1971). "Volunteers" for 
FGP received a non-taxable stipend of $\$ 2.20$ per hour, a hot meal, and transportation costs to and from the work site.

Senior Community Service Employment Program (SCSEP)

SCSEP provides federally-funded training and placement in subsidized social service jobs to persons aged 55 and older whose income does not exceed $\$ 5500-\$ 6800$, depending on the source of the income and size of the household. According to program guidelines, older women workers hired by SCSEP receive job training which will help them qualify for jobs in the regular workforce (Rix, 1984). The aim of the program is to place these persons in permanent, nonsubsidized jobs. Employees of SCSEP received the minimum wage of $\$ 3.35$ per hour.

\section{Work Sites}

The older women workers in this study held jobs in a variety of settings: participants in FGP held jobs in schools (11), health care settings (3), and day care facilities (2); participants in SCSEP held jobs in health care settings (6), correctional agencies (3), employment offices (3), and public welfare offices (4).

Co-workers held jobs as clerical or technical workers (e.g., secretaries and file clerks) or service providers (e.g., case managers, nurses, teachers, and child care workers) at the work sites with the older women workers. 
INTERVIEWERS

The interviews were conducted by two female advanced undergraduate and three female graduate students in psychology (including the author) at Portland state University. All had been trained in techniques for conducting semi-structured interviews and were familiar with the theoretical background for the study, which allowed them to probe for theoretically-related material in follow-up questions.

\section{INSTRUMENTS}

Pilot interviews consisting of broad, open-ended questions were conducted with three older women workers and their respective younger co-workers $(\underline{n}=6)$. The responses were analyzed for thematic content in order to develop a standard interview schedule for each group of women.

Interview schedules for both the older women workers and the co-workers consisted of standard questions with the potential for interviewers to pursue theoretically-relevant material with follow-up probes (Patton, 1980).

\section{Interview with older Woman Worker}

The interview with the older woman worker contained three sections of questions regarding her work for the agency and how she viewed her job. The older woman worker 
was asked how she felt she had affected her co-worker's job, what she perceived her co-worker's attitude to be toward her work, and how she felt the agency administration benefitted from the use of part-time workers. The older worker/coworker relationship in the workplace was explored with respect to alliances, conflicts, and sources of gratification and discontent.

A second section of the interview contained questions about family interactions relevant to the other half of the study which focused on family relationships.

The third section solicited demographic information (i.e., date of birth, marital status, extent of formal schooling, husband's occupation, preparation for work, work identity, and paid work history). The interview form is provided in Appendix $A$.

Interview with Younger Woman Co-Worker

The interview with the younger women co-worker was structured similarly to the interview with the older woman worker. The co-worker was first asked to describe the kind of work she did. The co-worker was questioned about her understanding of the older woman's work and how that work affected her own job.

Questions in the second section addressed any helpful or hindering interactions with the older woman worker at work, and whether the younger co-worker held any age-related 
or stereotypical expectations about the older woman's performance.

The third section contained questions on general working conditions emphasizing employee attitudes towards work and the workplace. Demographic information similar to that for the older woman worker was requested: date of birth, marital status, extent of formal schooling, husband's occupation, attitudes toward labor unions or employee associations, and length of time in present job. The interview form is provided in Appendix B.

\section{INTERVIEW PROCEDURE}

Consent was obtained from the program administrators to request volunteers for the study from among the older women workers at program meetings. The older women who expressed interest in the study were then contacted by telephone by the interviewers to inform them of the procedures of the study and to obtain nominations for the co-worker interviews. The younger co-workers were contacted first by the older women to obtain their cooperation, and then by the interviewer to arrange the interviews. With two exceptions, the same interviewer was able to complete both interviews for each older woman and co-worker dyad, which allowed themes linking the two interviews to be pursued. 
An attempt was made to have each interviewer conduct an equal number of interviews with subjects from FGP and SCSEP, but this was not possible because scheduling difficulties prohibited some interviewers from completing an equal number of interviews with each group while they were associated with the project.

Interviews with the older women workers and their coworkers were conducted separately, and whenever possible, took place away from the work settings at locations chosen by the subjects, usually at their homes or in restaurants. At the start of the interview, participants were asked to sign a consent form which explained the study, the confidentiality of responses and the right to withdraw from the study at any time. (Consent forms for the older women workers and the younger women co-workers are given in Appendix F.) The order of the work and family portions of the interview were reversed for half of the respondents. Interviews were tape-recorded for later transcription and lasted about 90 minutes for the older woman and 30 minutes for the co-worker. Field notes concerning the interview setting, general observations on the respondent and the interview process, and post-interview interactions were recorded by the interviewers following each interview. The interviews were completed between June 1987 and September 1988 . 


\section{CONTENT ANALYSIS}

After transcription, all interview data were subjected to content analysis to identify themes in the material. Some themes were found within only one data set, while others were identified within both the older women worker and co-worker responses. Forty-nine codes were developed to operationalize these themes: 19 codes for the older women workers, 18 codes for the younger women co-workers, and 12 codes which were common to both groups.

Codes which clustered with respect to the theoretical focus of the study were placed in conceptual categories. Six conceptual categories were formed for the older women: Good Feelings, Bad Feelings, Conflict, Sources of Satisfaction, Inequities, and Impact. These conceptual categories described the good or bad feelings the older woman had at work, types of conflict which arose in her job, sources of satisfaction she felt in her work, inequities she noticed in the treatment of her co-workers, and the impact her job had on the job of her younger co-worker.

Seven conceptual categories were defined for the younger co-workers: Help, Hinder, Positive, Negative, Conflict, Inequities, and Impact. These categories described the ways in which the older woman helped or hindered the co-worker in her work, positive or negative stereotypes which she might hold about older persons, types 
of conflict which arose in her job, inequities she noticed in the treatment of her co-workers, and the impact the older woman had on her job.

\section{CODING PROCEDURE}

As a result of the content analysis, two codebooks were written for use with the older woman worker and younger coworker interviews respectively. These coding manuals contained definitions of the codes, illustrated with examples which had been drawn from the interview data and modified, in order to preserve the original data for coding.

Two coders (who had also been interviewers for the study) were trained by the principal investigators of the larger study to identify codes in the interview material. Using transcripts of the pilot interviews, the coders practiced identifying the codes, after which they coded all the actual interview material.

The coders were aware of whether the interview was with a subject from FGP or SCSEP, and well as the identity of the interviewer.

The coding segment was the "response unit," defined as the uninterrupted response of the subject which followed the interviewer's question or comment. A theme was coded wherever it appeared, but not more than once per response 
unit. There was no restriction on the number of different codes which could be coded in one response unit.

Codes and interviews were recorded with a software program for the analysis of qualitative data, The Ethnograph (Seidel et al., 1988). This program provided alphabetized frequency listings of single or multiple codes for each interview which were used in the analysis of the data.

\section{Reliability of Coders (Cohen's kappa)}

Interrater reliability was assessed by computing Cohen's kappa (Cohen, 1960) on a subset of 10 of the older women worker interviews and 11 of the younger co-worker interviews which had been coded by both coders. The interviews selected for reliability checks were randomly chosen, and were balanced to represent interviews from both FGP and SCSEP. The coders were blind to the choice of interviews used for the calculation of reliability. on interviews which were checked for reliability, only agreements were retained for the purpose of coding. If the coders agreed that there were no codes in a response unit, this was counted as an agreement for the calculation of reliability. Kappas for the older women interviews ranged from .78 to .91 $(\underline{m}=.83)$, and for the younger co-worker interviews, from .84 to $1.0(\underline{m}=.90)$. 
Reliability of Coders (Percent Agreement)

Reliability of the coders for each code was assessed by computing percent agreements for each code across all the interviews. Codes were examined within the older women worker and younger co-worker interview groups separately. Percent agreement of codes for both the older women workers and the younger co-workers ranged from 0 to 100 percent. Coders were considered to have reached $100 \%$ agreement on a code when they agreed on the absence of that code within in interview as well as when they agreed on the presence of the code in the same response units throughout the interview.

For the older women workers, 12 codes met the reliability criterion of 60 percent agreement: RESPECT $(64 \%)$, SOLIDARITY $(75 \%)$, AMBIVALENT $(100 \%), \operatorname{BADINAD}(67 \%)$, BADSELF (100\%), CONCO (100\%), CONDEFEND (100\%), SATPAY (69\%), SATPURCH $(80 \%)$, SATPURSE $(90 \%), \operatorname{SATSTRUC}(67 \%)$, and IMPEMOT $(67 \%)$. Percent agreements for the codes for the older women workers are given in Table IV.

For the younger women co-workers, 17 codes met the reliability criterion of 60 percent agreement: HELPNURT (83\%), HELPSUP (78\%), HELPTECH (87\%), HINDACCOM (85\%), HINDAUTH (67\%), HINDINSEC (80\%), HINDPHIL (60\%), HINDPHYS (100\%), HINDRIG (80\%), HINDSLOW (100\%), POSEMOT (100\%), POSEXPER (67\%), NEGMENT (71\%), NEGPHYS (91\%), BADORG (85\%), CONOVER2 (100\%), and CONRESOLV (100\%). Percent agreements 
for the codes for the younger co-workers can be found in Table V.

\section{TABLE IV}

RELIABILITY: PERCENT AGREEMENT OF CODERS FOR EACH CODE ${ }^{1}$ (OLDER WOMEN WORKERS)

code $\% \mathrm{n}^{2}$

Good Feelings

RESPECT

SOLIDARITY

Bad Feelings

AMBIVALENT

BADINAD

BADSELF

Conflict

CONCO

CONDEFEND

\section{4}

75

25

4

Sources of Satisfaction

$\begin{array}{lrr}\text { SATPAY } & 69 & 13 \\ \text { SATPURCH } & 80 & 5 \\ \text { SATPURSE } & 90 & 10 \\ \text { SATSTRUC } & 67 & 6\end{array}$

\section{Impact}

$\begin{array}{lll}\text { IMPEMOT } & 67 & 3\end{array}$

100

100

3

$\begin{array}{ll}100 & 1 \\ 67 & 3\end{array}$

$100 \quad 4$

Notes: ${ }^{1}$ Calculation of reliability based on 10 randomlyselected interviews. See Appendix $\mathrm{E}$ for codes not reaching 60 percent agreement between coders.

${ }^{2}$ Number of agreements plus disagreements of coders. 
TABLE V

RELIABILITY: ${ }^{2}$ PERCENT AGREEMENT OF CODERS

FOR EACH CODE ${ }^{1}$ (YOUNGER WOMEN CO-WORKERS)

Code $\% \mathrm{n}^{2}$

Help

$\begin{array}{lll}\text { HELPNURT } & 83 & 18 \\ \text { HELPSUP } & 78 & 18 \\ \text { HELPTECH } & 87 & 30 \\ \text { HINDACCOM } & 85 & 26\end{array}$

Hinder

$\begin{array}{lrr}\text { HINDAUTH } & 67 & 6 \\ \text { HINDINSEC } & 80 & 5 \\ \text { HINDPHIL } & 60 & 5 \\ \text { HINDPHYS } & 100 & 6 \\ \text { HINDRIG } & 80 & 10 \\ \text { HINDSLOW } & 100 & 1\end{array}$

Positive

$\begin{array}{lrr}\text { POSEMOT } & 100 & 3 \\ \text { POSEXPER } & 67 & 3\end{array}$

Negative

$\begin{array}{lll}\text { NEGMENT } & 71 & 14 \\ \text { NEGPHYS } & 91 & 11\end{array}$

Conflict

$\begin{array}{lrr}\text { BADORG } & 85 & 61 \\ \text { CONOVER2 } & 100 & 0 \\ \text { CONRESOLV } & 100 & 2\end{array}$

Notes: ${ }^{1}$ Calculation of reliability based on 11 randomlyselected interviews. See Appendix $\mathrm{E}$ for codes not reaching 60 percent agreement between coders.

${ }^{2}$ Number of agreements plus disagreements of coders. 
For both the older and younger women, 7 codes met the reliability criterion of 60 percent agreement: CONCHALL (88\%), CONSTRAIN (92\%), CHEAP (86\%), PAYREL (79\%), PSYPAY (75\%), IMPPRESS (82\%) and IMPUP (72\%).

Percent agreements for the codes for both the older women workers and the younger women co-workers are given in Table VI.

\section{TABLE VI}

RELIABILITY: PERCENT AGREEMENT OF CODERS FOR EACH CODE ${ }^{1}$ [OLDER WOMEN WORKERS (OWW) AND

YOUNGER WOMEN CO-WORKERS (COW) $]^{2}$

Total $^{3}$

FGP

$\operatorname{SCSEP}$

Code

$\%$

n

$\%$

n

$\%$

n

Conflict

CONCHALL

CONSTRAIN

88

92
100

100
1

75

84
4

25

Inequities

CHEAP

PAYREL

PSYPAY
86

79

75
15

7

5
83
100
50

50
6

0

4

$\begin{array}{r}89 \\ 57 \\ \hline\end{array}$

100
9

7

1

Impact

IMPPRESS

IMPUP
82

72
72

24
75

56
28

9

89

87
44

15

Notes: ${ }^{1}$ See Appendix $E$ for codes not reaching 60 percent agreement between coders.

${ }^{2}$ calculation of reliability based on 10 (for OWW) and 11 (for cow) randomly-selected interviews.

${ }^{3}$ Mean value of percent agreements $(\%)$ and sum of number of agreements plus disagreements of coders. 
Codes which did not reach 60 percent agreement, the criterion for inclusion in the analysis of results, appear in Tables XI and XII of Appendix E.

\section{CODING SYSTEM}

A brief description of each code which met the reliability criterion of at least 60 percent agreement is given below, alphabetically within its conceptual category. Twelve codes are listed for the older women workers, 17 for the younger women co-workers, and 7 codes for both groups. Complete operational definitions of all the codes, including those which did not meet the reliability criterion, appear with quotes from the coded interview material in the Codebook for the older Women Workers in Appendix $C$ and the Codebook for the Younger Women Co-workers in Appendix D.

Codes for the older Women Workers

Good Feelings. The conceptual category "Good Feelings" contains codes which reflect the pleasurable feelings the older women workers gained by being in the workplace.

RESPECT (Respect). Being respected for one's specific skill or knowledge in the workplace.

SOLIDARITY (Solidarity). Expressing solidarity with co-workers in their difficulties in the workplace. 
Bad Feelings. The conceptual category "Bad Feelings" contains codes which reflect the unpleasant feelings the older women had while in the workplace.

AMBIVALENT (Ambivalent). Feeling good, but somewhat ambivalent about receiving praise; sense of being manipulated by expressions of gratitude.

BADINAD (Bad-Inadequate). Concern with feeling inadequate; having difficulty keeping up with demands of the workplace.

BADSELF (Bad-Self). Concern with being treated badly, disrespectfully, or being patronized by staff or clients.

Conflict. Codes found in the conceptual category "Conflict" refer to conflict which arose in the workplace. CoNCo (Conflict-Co-Worker). Conflict with co-workers, other regular staff; feelings of isolation, competition, hostility.

CONDEFEND (Conflict-Defend). Conflict with defending limits of own work role; pressure from others in the workplace to work outside program guidelines, beyond assigned hours of work, or not take breaks.

sources of Satisfaction. The conceptual category "Sources of Satisfaction" contains codes which describe the ways in which the older woman's work was satisfying to her. SATPAY (Satisfaction-Pay). Economic reward of work in pay or benefits; mention of income as a benefit of working. 
SATPURCH (Satisfaction-Purpose-Challenge). Specific sense of purpose in providing activity that is inherently interesting or challenging.

SATPURSE (Satisfaction-Purpose-Serve). Specific sense of purpose in providing service and doing work which is useful.

SATSTRUC (Satisfaction-Structure). Structure provided by work; provides a place to go, something to do, way to keep busy; alternative to doing nothing.

Impact. Codes found in the conceptual category "Impact" refer to the ways in which the older woman perceived her work to be affecting that of her younger woman co-worker.

IMPEMOT (Impact-Emotional). Older woman takes over the nurturant component of emotional labor, allowing co-worker to be more involved in disciplinary activity.

Codes for the Younger women co-Workers

Help. The conceptual category "Help" contains codes which describe the ways in which the younger co-worker felt the older woman helped her in the workplace.

HELPNURT (Help-Nurturant). Provides a nurturant function in relation to clients, or creates a family atmosphere in the work setting.

HELPSUP (Help-Support). Provides emotional support or advice to co-worker or other staff. 
HELPTECH (Help-Technical). Provides technical assistance in carrying out tasks in the workplace.

HINDACCOM (Hinder-ACCommodate). Creates special

demands on the co-worker, who feels obligated to accommodate or adapt to special needs of older woman. (Placement of HINDACCOM in the "Help" category was based on statements by the younger women co-workers concerning the older women workers' usefulness in the workplace, despite their occasional need for special consideration.)

Hinder. The conceptual category "Hinder" contains codes which describe the ways in which the younger co-worker felt the older woman hindered her in the workplace. codes which describe the ways the younger co-worker HINDAUTH (Hinder-Authority). Does not project authority; is unable to handle situations which require discipline or behavioral intervention.

HINDINSEC (Hinder-Insecure). Is insecure, doesn't have confidence to learn, or is limited by situational factors. May be component of empathy.

HINDPHIL (Hinder-Philosophy). Does not understand philosophy of agency; works in a way which conflicts with agency goals.

HINDPHYS (Hinder-Physical). Is physically slow, incapacitated, prone to illness; references to impairment of senses (e.g., hearing, eyesight). 
HINDRIG (Hinder-Rigid). Is rigid, resists change, does not want to learn new tasks or new philosophy of work. HINDSLOW (Hinder-slow). Is slow, passive, lacks initiative or ability to respond.

Positive. The conceptual category "Positive" contains codes which concern positive stereotypes of aging.

POSEMOT (Positive-Emotional). Older persons have positive emotional characteristics which make them pleasant to be around.

POSEXPER (Positive-Experience). Older persons have had important life experiences or job-related experiences that benefit others in the workplace.

Negative. The conceptual category "Negative" contains codes which concern negative stereotypes of aging. NEGMENT (Negative-Mental). Older persons are slow mentally, rigid, insecure, childlike, lack initiative, have difficulty learning complex or technical tasks.

NEGPHYS (Negative-Physical). Older persons are physically slow, more prone to illness, likely to have impaired senses (e.g., hearing, eyesight).

Conflict. Codes found in the conceptual category "Conflict" refer to conflict which arose in the workplace.

BADORG (Bad-organization). Concern with problems within the organization; difficulties with management; difficult working conditions; staff interpersonal conflicts. 
CONOVER2 (Conflict-Overstep-2). Conflict with overstepping boundaries of own work role; desire to have more authority or responsibility.

CONRESOLV (Conflict-Resolve). When conflict arises with other co-workers or older woman, co-worker feels there are ways of resolving or addressing issues.

Codes for Both older Women Workers and Younger Women CoWorkers

Conflict. Codes found in the conceptual category "Conflict" refer to conflict which arose in the workplace. CONCHALL (Conflict-Challenge). Conflict over lack of challenge in the job, lack of opportunity to learn new skills.

CONSTRAIN (Conflict-Strain). Conflict over physical or emotional strain of job.

Inequities. The conceptual category "Inequities" contains codes which refer to the perception of unfairness in the treatment of the older woman in the workplace.

CHEAP (Cheap). Older worker is source of cheap labor for the organization.

PAYREL (Pay-Relative). older worker not paid well relative to other workers in setting.

PSYPAY (Psychic-Pay). Low pay is justified by emphasizing "psychic pay," or inherent gratification in the work. 
Impact. Codes found in the conceptual category "Impact" refer to the ways in which the older woman's work was perceived to be affecting that of her younger woman coworker.

IMPPRESS (Impact-Pressure). Older woman worker reduces pressure or overload on co-worker by allowing co-worker to do more of the same type of work. Coded wherever IMPUP occurred.

IMPUP (Impact-Upgrade). Older woman upgrades coworker's work by taking over lower level tasks, freeing coworker to do more important work. 


\section{RESULTS}

The results of this study follow from a content analysis of semi-structured interviews conducted with older women who worked part-time in social service work $(n=32)$ and their younger women co-workers who worked full-time $(n=32)$. The women were employed in the Foster Grandparent Program (FGP) and the Senior Community Service Employment Program (SCSEP). (Data on the characteristics of the respondents and information about the interview coding procedure, including the assessment of reliability, are given in the Method section of this thesis.)

All of the interviews produced useable codes, but only codes which reached a reliability of 60 percent agreement of coders were included in the analysis of results. Nineteen codes for the older women workers and 24 codes for the younger women co-workers met the reliability criterion of 60 percent agreement. Of these codes, 7 were common to both the older women workers and the younger women co-workers. (A brief description of the codes is given at the end of the Method section of this thesis, and a more detailed description, with examples from the interviews, in Appendices $C$ and D.) 
IMPACT OF THE OLDER WOMEN WORKERS ON THE WORK

OF THE YOUNGER WOMEN CO-WORKERS

Thirty $(94 \%)$ of the older women and $32(100 \%)$ of the co-workers mentioned at least one of the codes in the conceptual category "Impact," relating to whether the older woman's presence had affected the work of her co-worker. one hundred percent of the older women workers and 88 percent of the younger women co-workers mentioned IMPPRESS; 66 percent of the older women workers and 44 percent of the younger women co-workers mentioned IMPUP. Additionally, the code IMPEMOT was mentioned by 34 percent of the older women workers; IMPEMOT was not identified in the responses of the younger women co-workers. The percentage of both older women workers and younger women co-workers who mentioned each code is given in order of frequency in Table VII.

An examination of dyads of older women and the younger co-workers with whom they had immediate contact showed that in 28 of 32 dyads (88\%), both persons had recognized and reported that the older woman reduced the pressure of the workload on the co-worker by her presence (IMPPRESS). A binomial test of the hypothesis that matched pairs of older women workers and their younger women co-workers would agree by naming IMPPRESS above the rate of chance was significant at the .005 level (27 of 32 pairs). Examining the matched pairs of older women and younger co-workers who both 
TABLE VII

PERCENTAGE OF OLDER WOMEN WORKERS (OWW)
AND YOUNGER WOMEN CO-WORKERS (COW)
MENTIONING "IMPACT" CODES

Total

$(n=64)$

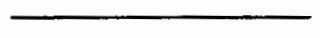

Code

\begin{tabular}{cc}
\hline OWW & COW \\
$\%$ & $\%$
\end{tabular}

\section{Impact}

IMPPRESS

IMPUP

IMPEMOT
$88 \quad 100$

$44 \quad 66$

34
FGP

$(n=32)$

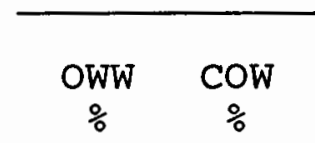

SCSEP

$(n=32)$

\begin{tabular}{|c|c|}
\hline $\begin{array}{l}\text { OWW } \\
0\end{array}$ & COW \\
\hline
\end{tabular}

mentioned IMPPRESS by program showed that 13 of the matched pairs occurred in the Foster Grandparent Program (FGP), and 15 in the Senior Community Service Employment Program (SCSEP) •

A dyadic analysis of the code IMPUP showed that 10 of 32 pairs (31\%) of the matched older women and co-workers agreed that the older woman's presence had had the effect of upgrading her co-worker's work (IMPUP). A binomial test of the proportion of matched pairs agreeing on IMPUP was not significant. Of the 10 pairs which matched on IMPUP, 5 were in FGP and 5 in SCSEP.

Chi-square tests to determine whether there were program differences (between respondents in FGP and SCSEP) or intergenerational differences (between the older women workers and the younger women co-workers) in the number of 
women who mentioned IMPPRESS and IMPUP were not significant. sixty-nine percent of the older women workers in the Foster Grandparent Program mentioned that they had had an impact on their younger co-workers' work by taking over the emotional component of the labor (IMPEMOT); no older women in SCSEP mentioned this code. (IMPEMOT did not emerge as a code for the younger women co-workers in either program.) A chi-square test to determine whether there were program differences between respondents in FGP and SCSEP in the number of older women workers who mentioned IMPEMOT was significant at $\underline{x}^{2}=13.85, \underline{p}<.001$ (Yates-corrected), df 1 .

\section{PROGRAM DIFFERENCES (FGP and SCSEP)}

Rank order correlations (Spearman's rho) (Ferguson, 1981) of the codes mentioned by respondents in FGP and SCSEP were calculated to determine whether program differences existed between the FGP and SCSEP work settings for both the older women workers and their younger women co-workers. For the older women workers, tho was significant at $\mathrm{p}<.02, \underline{t}=$ 2.72, df 17 , showing that there was a significant difference in the codes mentioned by the older women workers in FGP and SCSEP. For the younger women co-workers, rho was significant at $\mathrm{p}<.01, \underline{t}=3.54$, df 21 , also indicating a significant difference in the codes mentioned by the younger women co-workers in the two programs. 


\section{INTERGENERATIONAL RELATIONSHIPS}

\section{Perceptions of the older Women Workers}

The older women's perceptions of the emotional tone of the relationship between themselves and their younger coworkers in the workplace were inferred from their responses to questions about interactions with their younger coworkers. These were coded in the conceptual categories "Good Feelings," "Bad Feelings," "Conflict," and "Sources of Satisfaction" (see Method section for a description of these categories) .

Respect for their work contribution (RESPECT) (81\%) was the code most frequently mentioned by the older women workers within the conceptual category "Good Feelings" (and within the older women data set). Only 3 percent of the older women, all in SCSEP, reported feelings of solidarity with other workers in gaining more respect or control in the workplace (SOLIDARITY). Chi-square tests for program differences between older women workers in FGP and SCSEP who mentioned RESPECT and SOLIDARITY were not significant.

Within the conceptual category "Bad Feelings," the older women workers mentioned feeling inadequate (BADINAD) (25\%) and feeling badly treated at work (BADSELF) (16\%). six percent of the older women felt ambivalent about the praise they received at work (AMBIVALENT); this response was found equally in both groups. Chi-square tests for program 
differences between older women workers in FGP and SCSEP who mentioned BADINAD, BADSELF, and AMBIVALENT were not significant.

The conceptual category "Conflict" contained two codes: conflict with others in the workplace (CONCO) (25\%), reported equally by both groups, and conflict in defending the limits of the work role from pressure to work outside program guidelines (CONDEFEND) (9\%) reported only by Foster Grandmothers. Chi-square tests for program differences between older women workers in FGP and SCSEP who mentioned CONCO and CONDEFEND were not significant.

"Sources of Satisfaction" in the workplace for the older women were satisfaction with receiving payment for their work (SATPAY) (72\%), satisfaction with work which was seen as inherently interesting (SATPURCH) (16\%), a sense of purpose in serving others (SATPURSE) (59\%), and satisfaction with the structure provided by work (SATSTRUC) (25\%). Chisquare tests for program differences between older women workers in FGP and SCSEP who mentioned SATPAY, SATPURCH, SATPURSE, and SATSTRUC were not significant.

The percentage of older women workers who mentioned each code is given in Table VIII.

Perceptions of the Younger Women Co-Workers

The younger women co-workers' perceptions of the emotional tone of the intergenerational relationship were 
TABLE VIII

PERCENTAGE OF OLDER WOMEN WORKERS

MENTIONING "INTERGENERATIONAL RELATIONS" CODES

\begin{tabular}{|c|c|c|}
\hline $\begin{array}{l}\text { Total } \\
(n=32)\end{array}$ & $\begin{array}{c}\text { FGP } \\
(n=16)\end{array}$ & $\begin{array}{c}\text { SCSEP } \\
(n=16)\end{array}$ \\
\hline$\%$ & $\%$ & $\%$ \\
\hline
\end{tabular}

Good Feelings

\begin{tabular}{|c|c|c|c|}
\hline RESPECT & 81 & 81 & 81 \\
\hline SOLIDARITY & 3 & 0 & 6 \\
\hline M of other codes & 68 & 94 & 44 \\
\hline
\end{tabular}

Bad Feelings

AMBIVALENT

6

6

6

BADINAD

25

BADSELF

31

M of other $\operatorname{codes}^{1} \quad 24$

Conflict

CONCO

M of other codes
M
25

9

27
25

19

40
25

15

Sources of Satisfaction

\begin{tabular}{|c|c|c|c|}
\hline SATPAY & 72 & 88 & 5 \\
\hline SATPURCH & 16 & 6 & 2 \\
\hline SATPURSE & 59 & 75 & 4 \\
\hline SATSTRUC & 25 & 38 & $1:$ \\
\hline$M$ of other codes ${ }^{\perp}$ & 37 & 46 & $2 \varepsilon$ \\
\hline
\end{tabular}

Note $^{1}$ : See Appendix $\mathrm{E}$ for codes not reaching 60 percent agreement between coders.

inferred from their responses to questions about interactions with the older women workers. These were coded in the conceptual categories "Help," Hinder," "Positive," "Negative," and "Conflict" (see Method section for a 
description of these categories). An examination of the data revealed that negative responses (i.e., codes in the conceptual categories "Hinder" and "Negative") were not concentrated in a small number of respondents but were distributed across respondents and programs. Three respondents in FGP and one respondent in SCSEP mentioned no codes in either the "Hinder" or "Negative" conceptual categories. All respondents $(n=32)$ mentioned at least one code in the "Help" or "Positive" conceptual categories.

Within the conceptual category "Help," help provided by the older women workers with the technical aspects of the work (HELPTECH) was cited by 97 percent of the younger women co-workers. Help provided by the older women workers in the form of emotional support or advice was mentioned by 50 percent of the younger women co-workers (HELPSUP). Fortyseven percent of the co-workers reported that the older women helped them with the nurturant aspects of their work (HELPNURT). Forty-four percent of the younger women coworkers said that the older woman should be accommodated in the workplace although she created special demands on her co-workers (HINDACCOM). Chi-square tests for program differences between younger women co-workers in FGP and SCSEP who mentioned HELPTECH, HELPSUP and HINDACCOM were not significant; a chi-square test for HELPNURT was significant at $\underline{x}^{2}=21.21, \underline{p}<.001$ (Yates-corrected), df 1 . 
The conceptual category "Hinder" was composed of six codes which described how the older women workers hindered the younger women co-workers in their jobs by lacking in authority (HINDAUTH) (9\%), lacking confidence (HINDINSEC) (28\%), working in ways which conflicted with agency goals (HINDPHIL) (19\%), being physically impaired (HINDPHYS) (9\%), being rigid or resistant to change (HINDRIG) (6\%), and being passive or slow (HINDSLOW) ( $9 \%$ ). Chi-square tests for program differences between younger women co-workers in FGP and SCSEP who mentioned HINDAUTH, HINDINSEC, HINDPHYS, HINDRIG, and HINDSLOW were not significant; a chi-square test for HINDPHIL was significant at $\underline{x}^{2}=5.13, \underline{p}=.024$ (Yates-corrected), df 1 .

The existence of positive or negative ageist stereotypes held by the younger women co-workers were expressed in codes which were placed in the conceptual categories "Positive" and "Negative."

"Positive" conceptualizations of older persons as possessing positive emotional qualities (POSEMOT) and as having had valuable life and work experiences (POSEXPER) were mentioned by 34 and 47 percent of the younger coworkers, respectively. Chi-square tests for program differences between younger women co-workers in FGP and SCSEP who mentioned POSEMOT and POSEXPER were not significant. 
"Negative" conceptualizations of older persons involved reporting them as showing impairment mentally (NEGMENT) and physically (NEGPHYS), both mentioned by 44 percent of the younger women co-workers. Chi-square tests for program differences between younger women co-workers in FGP and SCSEP who mentioned NEGMENT and NEGPHYS were not significant.

Within the conceptual category "Conflict," the coworkers mentioned their concern with organizational problems (BADORG) (69\%), frustrations with the constraints of their own jobs (CONOVER2) (3\%), and confidence in their ability to resolve work conflicts (CONRESOLV) (34\%). Chi-square tests for program differences between younger women co-workers in FGP and SCSEP who mentioned BADORG, CONOVER2, and CONRESOLV were not significant.

The percentage of younger women co-workers who mentioned each code is given in Table IX.

Perceptions of the older Women Workers and Younger Women CoWorkers

Codes which were mentioned in both the older woman worker and younger co-worker data sets appeared in the conceptual categories "Conflict," which concerned conflictual interaction in the workplace, and "Inequities," which concerned the awareness (or lack of awareness) of unequal treatment of the older women workers by others in 
TABLE IX

PERCENTAGE OF YOUNGER WOMEN CO-WORKERS

MENTIONING "INTERGENERATIONAL RELATIONS" CODES

$$
\begin{array}{lcc}
\text { Total } & \text { FGP } & \text { SCSEP } \\
(n=32) & (n=16) & (n=16)
\end{array}
$$

Code

$\%$

$\%$

$\%$

Help

$\begin{array}{lrrr}\text { HELPNURT } & 47 & 88 & 6 \\ \text { HELPSUP } & 50 & 50 & 50 \\ \text { HELPTECH } & 97 & 100 & 94 \\ \text { HINDACCOM } & 44 & 44 & 44\end{array}$

Hinder

HINDAUTH

9

19

0

HINDINSEC 28

25

31

HINDPHIL

19

38

HINDPHYS

9

13

0

HINDRIG

6

HINDSLOW

9

M of other codes ${ }^{1} \quad 16$

Positive

POSEMOT

POSEXPER

$\begin{array}{ll}\text { POSEXPER } & 47 \\ \text { M of other codes } & 28\end{array}$
34
38

38

13
31

56

44

Negative

NEGMENT 44

38

50

NEGPHYS 44

M of other codes ${ }^{1} \quad 19$

19

Conflict

BADORG

CONOVER2

CONRESOLV
69

3

19
50

6

25
88

0

13

Note ${ }^{1}$ : See Appendix $\mathrm{E}$ for codes not reaching 60 percent agreement between coders. 
the workplace, including the organizational management. within the conceptual category "Conflict," conflict over the lack of challenge in the work was mentioned by the older women and their younger co-workers equally (CONCHALL) (13\%). A feeling of physical or emotional strain from the job (CONSTRAIN) was mentioned by 16 percent of the older women and 34 percent of the co-workers. Chi-square tests for program differences between older women workers in FGP and SCSEP who mentioned CONCHALL and CONSTRAIN were not significant. Chi-square tests for program differences between younger women co-workers in FGP and SCSEP who mentioned CONCHALL and CONSTRAIN also were not significant. Chi-square tests for intergenerational differences between older women workers and younger women co-workers who mentioned CONCHALL and CONSTRAIN were not significant.

Within the conceptual category "Inequities," 59 percent of the older women and 47 percent of their younger coworkers expressed an awareness that the older women were a source of cheap labor for their organizations (CHEAP). Recognition that the older women were paid less relative to others in the setting (PAYREL) was mentioned by 50 percent $f$ the co-workers and 9 percent of the older women. The inherent gratification of the work itself as a substitute for pay (PSYPAY) was mentioned by 9 percent of the older women and 13 percent of the co-workers. Chi-square tests 
for program differences between older women workers in FGP and SCSEP who mentioned PAYREL and PSYPAY were not significant; a chi-square test for CHEAP was significant at $\underline{x}^{2}=4.66, \underline{p}=.031$ (Yates-corrected), df 1 . Chi-square tests for program differences between younger women coworkers in FGP and SCSEP who mentioned CHEAP, PAYREL, and PSYPAY were not significant.

Chi-square tests for intergenerational differences between older women workers and younger women co-workers who mentioned CHEAP and PSYPAY were not significant; a chisquare test for PAYREL was significant at $\underline{x}^{2}=10.78, \underline{p}=$ .001 (Yates-corrected), df 1 .

The percentage of both older women workers and younger women co-workers who mentioned each code can be found in Table $x$.

Dyadic analyses of each code from the conceptual category "Conflict" gave the following results: CONSTRAIN, 2 matched pairs. Dyadic analyses of each code from the conceptual category "Inequities" gave the following results: CHEAP, 9 matched pairs; PAYREL and PSYPAY, 1 matched pair each. Binomial tests of the hypothesis that matched pairs of older women workers and their younger co-workers would agree by naming each of the codes in the conceptual categories "Conflict" and "Inequities" above the rate of chance were not significant. 
TABLE X

PERCENTAGE OF OLDER WOMEN WORKERS (OWW) AND YOUNGER WOMEN CO-WORKERS (COW) MENTIONING "INTERGENERATIONAL RELATIONS" CODES

Total

$(n=64)$

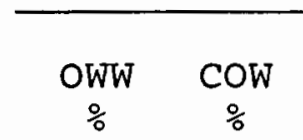

FGP

$(n=32)$

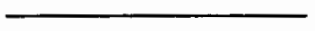

Code

(1)

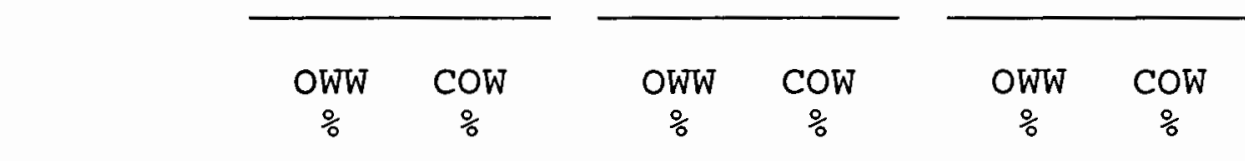

Conflict

\begin{tabular}{|c|c|c|c|c|c|c|}
\hline CONCHALL & 13 & 13 & 6 & 13 & 19 & 13 \\
\hline CONSTRAIN & 16 & 34 & 25 & 19 & 6 & 50 \\
\hline$M$ of other codes & 27 & - & 40 & - & 15 & . \\
\hline
\end{tabular}

\section{Inequities}

$\begin{array}{lrrrrrr}\text { CHEAP } & 59 & 47 & 38 & 50 & 81 & 44 \\ \text { PAYREL } & 9 & 50 & 6 & 38 & 13 & 63 \\ \text { PSYPAY } & 9 & 13 & 19 & 25 & 0 & 0 \\ \text { M of other codes } & 127 & 16 & 32 & 17 & 25 & 15\end{array}$

Note ${ }^{1}$ : See Appendix $\mathrm{E}$ for codes not reaching 60 percent agreement between coders.

IMPACT OF PERCEIVED CHANGES IN THE CO-WORKERS' WORK ON INTERGENERATIONAL RELATIONSHIPS IN THE WORKPLACE

Chi-square tests of independence were calculated to test whether the perception that the co-workers' work was changed by the entry of the older women into the work force affected intergenerational relationships.

Chi-square tests of independence were calculated for 1) the code IMPUP versus a mention of any of the codes in the conceptual category "Help" (null hypothesis: there is no relationship between the older women's upgrading of the 
co-workers' work and the co-workers' mention of ways the older women helped them in their work), and for 2) the code IMPUP versus a mention of any of the codes in the conceptual category "Hinder" (null hypothesis: there is no relationship between the older women's upgrading of the coworkers' work and the co-workers' mention of ways the older women hindered them in their work). The tests were not significant, supporting the null hypothesis of no relationship.

Two further chi-square tests of independence were calculated to test the relationship between positive or negative ageist stereotypes held by the younger women coworkers and the co-workers' mention of the ways the older women helped or hindered them in their work. The chi-square tests were of 1) a mention of any of the codes in the conceptual category "Hinder" versus a mention of any of the codes in the conceptual category "Negative," (null hypothesis: there is no relationship between the younger co-workers' mention of the older women workers' hindering the performance of their work and their mention of negative ageist stereotypes) and 2) a mention of any of the codes in the conceptual category "Help" versus a mention of any of the codes in the conceptual category "Positive" (null hypothesis: there is no relationship between the younger co-workers' mention of the older women workers' helping in 
the performance of their work and their mention of positive ageist stereotypes). The tests were not significant, supporting the null hypothesis of no relationship. 


\section{DISCUSSION}

The 64 interviews with older women workers and their younger women co-workers generated a large quantity of interesting data which provided insights into intergenerational relations in the workplace. The following discussion of the results of this study will focus on codes which both satisfied the reliability criterion and were found to show a significant difference in the number of respondents who mentioned the codes by programs (FGP and SCSEP) or by generations (older women workers and younger women co-workers) .

\section{IMPACT OF THE OLDER WOMEN'S WORK}

The impact of the older women's work on the work of their younger co-workers was recognized by both generations, in both programs, although the older women would have had no direct knowledge of how their co-workers' work was performed before they entered the workplace. The significant agreement of dyadic responses suggests that the older women may have been reflecting the perceptions of their younger co-workers concerning a reduction in work pressure on the co-workers (IMPPRESS). A grateful co-worker would be likely 
to mention that her job was easier with the older woman working at the site.

Likewise, the older woman might not have been able to observe directly whether her presence upgraded the work of her co-worker (IMPUP). If the co-worker no longer performed the essential tasks, but left them to the older woman, an upgrading effect might be assumed. On the other hand, if the older woman were performing work which had not been done previously by the co-worker, there would be no upgrading effect. The lack of significant agreement between the older women workers and the younger women co-workers possibly could reflect this latter case. In no case did either the older women or the younger co-workers report that the older woman had downgraded the work of the co-worker, which could be expected, based on the younger co-workers' higher level of education as well as their longer job tenure.

The code IMPEMOT, which is defined as the taking over by the older women workers of the emotional component of the work from the younger co-workers, was significant in a chisquare test of program differences, yet it also should be mentioned as an "Impact" code which describes how the work of the older women affected their younger co-workers. Because most of the SCSEP workers were not doing work which had an emotional component as obvious as that of the FGP 
older women, this code was not mentioned by older women workers in SCSEP.

\section{PROGRAM DIFFERENCES (FGP AND SCSEP)}

The finding that participants in the Foster Grandparent Program (FGP) and the Senior Community Service Employment Program (SCSEP) and their younger women co-workers differed significantly by program in the rank order of the number of respondents mentioning each code ( $\underline{\text { rho }}$ ) suggests that women in FGP and SCSEP had different concerns about their work, which they expressed by mentioning different codes. Given the different objectives of these two programs (caring for young children versus training for placement in subsidized social service jobs), this result was not entirely unexpected.

Had rho not been significant, it would have been possible to argue that the significant difference in age between the older women workers in the two programs (reported in the Method section) was not a confounding variable with program differences. This would have allowed conclusions to be generalized to participants in both programs, regardless of their age differences.

Despite the statistically-significant difference in the rank ordering of codes mentioned by women in each program, the percentage of respondents mentioning individual codes, 
such as RESPECT ( $81 \%$ for older women workers in both FGP and SCSEP) and HELPTECH (100\% for younger co-workers in FGP and $94 \%$ for younger co-workers in SCSEP) point up the areas of agreement between women in both programs.

\section{older Women Workers}

With respect to program differences for individual codes, the responses of older women workers in FGP and SCSEP differed significantly for only 2 codes out of 19: CHEAP and IMPEMOT.

Recognition that they were a source of cheap labor for their organizations (CHEAP) was mentioned significantly more often by older women workers in SCSEP (81\%) than in FGP (38\%). This finding would be expected given the nature of the two programs. Older women working for SCSEP were totally dependent on the money they were earning to cover their living expenses, while FGP older women were allowed by their program to maintain some small financial reserves. Women in SCSEP were younger than those in FGP, and were often not yet eligible to draw social security benefits.

Older women in the Foster Grandparent Program mentioned taking over the emotional component of the work (IMPEMOT) from the younger co-workers $(69 \%)$, a result which differed significantly from respondents in SCSEP, who did not mention this code at all. Again, the nature of the work performed by the FGPs, who frequently spent their working hours acting 
as "grandmothers" to children in schools or hospitals, would explain this result.

\section{Younger Women Co-Workers}

Significant program differences were found for 2 out of 24 codes for the younger women co-workers: HELPNURT and HINDPHIL. Both codes were more frequently mentioned by younger co-workers in FGP.

The younger co-workers in FGP recognized the nurturant function performed by the older women workers for that program (HELPNURT) (88\%), significantly more frequently than did co-workers in SCSEP $(6 \%)$. The younger co-workers in FGP described the Foster Grandmothers as providing direct attention, with a nurturant component, to the children with whom they worked.

Co-workers in FGP also described how the older women workers in that program did not understand the philosophy of the work site agencies, and how they seemed to work in a way which conflicted with agency goals (HINDPHIL) (38\%). This tendency was not mentioned by any younger co-workers in SCSEP, and may be related to the older women's work preparation (see Table II). Older women in SCSEP overwhelmingly mentioned paid work as preparation for their current jobs; Foster Grandmothers were more likely to mention their experience in the home, or in volunteer positions. Perhaps the older women workers in FGP felt 
their experience gave them insight into the goals of the schools and hospitals where they performed their work of caring for children, and they felt free to express their differences with those goals, which would be noticed by their younger co-workers.

\section{INTERGENERATIONAL DIFFERENCES}

(OLDER WOMEN WORKERS AND YOUNGER WOMEN CO-WORKERS)

The analysis of the intergenerational relationship between the older women workers and their younger women coworkers was restricted to the 7 codes mentioned by both generations which were found to be reliable. of these, only the awareness that the older women workers were being paid less than others doing similar jobs in the work setting (PAYREL) was significantly different for older women workers than it was for younger co-workers.

Co-workers in both FGP (38\%) and SCSEP (63\%) acknowledged the inequality in the older women's pay relative to others in the workplace, while the older women were not as aware of this inequality. The co-workers had been in their work situations longer than the older women with whom they worked, and held full-time positions compared to the half-time jobs held by the older women workers. These two conditions would have made the younger co-workers more likely than the older women to be aware of pay discrepancies in the workplace. 
Additionally, 15 of the 32 younger women co-workers held memberships in labor unions or professional associations, which may have increased their sensitivity to the pay inequities which existed, although many of them professed indifference to union activities (see Table III).

\section{INTERGENERATIONAL RELATIONSHIPS}

The preceding discussion has focused on the ways in which the perceptions of the two generations diverged, and on differences in the concerns of the older and younger women working in FGP and SCSEP.

A different analysis might have reflected the ways in which the perceptions of the two generations converged. Despite the differences in educational level, job level, age, marital status, and a number of other demographic variables, several codes were found which addressed the common concerns of the respondents. The older women workers' awareness that they were being used as cheap labor (CHEAP) in SCSEP is complemented by the younger co-workers' recognition that the older women were being paid less than others at the work site (PAYREL).

Within the Foster Grandparents Program, the older women workers' statements that they had taken over the emotional component of labor, freeing their younger women co-workers for other tasks (IMPEMOT) was acknowledged by those co- 
workers in their mentions of how the older women helped them in their work by taking on nurturing tasks (HELPNURT).

IMPACT OF PERCEIVED CHANGES IN THE CO-WORKERS' WORK ON INTERGENERATIONAL RELATIONSHIPS IN THE WORKPLACE

Chi-square tests of the relationship between the younger women co-workers' mentioning that the older women had upgraded the co-workers'work and their mentioning ways in which the older women workers helped or hindered them in their work was not significant. Significant results on these tests would have suggested that a perceived upgrading of the co-workers' work was associated with mention of helpful or hindering actions of the older women which might affect intergenerational relations in the workplace.

A second set of chi-square tests to examine the relationship between positive or negative ageist stereotypes held by the younger women co-workers and the co-workers' mention of how the older women helped or hindered them in their work were also not significant. significant results on these tests would have suggested that the holding of ageist stereotypes by the younger women co-workers was associated with mention of helpful or hindering actions of the older women which might also affect intergenerational relationships.

Although the statistical tests of the impact of the older women's work on intergenerational relations in the 
workplace were not significant, the significant program differences found for the individual codes IMPEMOT (the older women workers described how they took over the emotional component of their younger co-workers' work) and HELPNURT (the younger women co-workers described how the older women workers helped by performing a nurturant function in the work setting) show that, at least for women in FGP, the entry of the older women into the workplace had a good effect on their relationship with their younger women co-workers.

\section{LIMITATIONS OF THE STUDY}

Any discussion of the results of this study must be accompanied by a discussion of the limitations of the data and the way in which the data were collected and analyzed. The manner in which subjects were selected for this study places a potential constraint on interpretation of the data. Specifically, the older women workers who volunteered to participate in the study were asked to select the younger woman with whom they worked most closely to also participate as a subject. A younger woman co-worker with whom the older woman did not have a good relationship would probably not be asked to participate, nor would she be likely to agree to serve as a subject for the study. 
Because of the way in which subjects were selected, data collected from the younger co-workers could be expected to reflect positively on the older woman and her work. Therefore, it is remarkable that negative comments were expressed by the younger co-workers (in the codes which appeared in the conceptual categories "Hinder" and "Negative"), and that these responses were not made by isolated individuals, but were spread across the sample. The balanced wording of the questionnaire, which asked the respondents to discuss both positive and negative aspects of the interaction with the older women, as well as the assurance of confidentiality, may have allowed this freedom of response.

Another possible influence on the data collection was the length of time which occasionally elapsed between interviews, caused by scheduling difficulties. Half of all interview pairs were completed within one week, but in one instance, 8 months elapsed between the interview with the older woman and her younger co-worker. It is not possible to determine whether waiting to do the second interview had an effect on the data because there may also have been a confounding effect of the interviewers who conducted the interviews.

While using a semi-structured interview with open-ended questions made the estimation of reliability difficult, it 
did allow the collection of data which might not have been gathered by other methods. Reference to the tables for reliability (Tables IV, V, and VI), and the percentage of respondents mentioning codes (Tables VII, VIII, IX, and X) can help the reader interpret the results.

\section{ISSUES OF RELIABILITY AND VALIDITY}

The results of this study were derived from codes produced by analyzing semi-structured interviews with older women and their younger women co-workers; any discussion of these codes must mention the issue of their reliability and validity

\section{Validity of the subjects' Responses}

As mentioned earlier in the Discussion section, the younger co-workers would be likely to avoid discussing the more negative aspects of their relationship with the older women workers, because the older women had selected them. The older women workers would be likely to state that they were satisfied with their relationship with their younger co-worker, because they were already on sufficiently good terms to ask the younger co-worker to serve as a subject for the study. For these reasons, the older women workers and their younger women co-workers who were the respondents for this study were a potential source of invalid responses to questions posed by the interviewers, if they practiced 
deliberate evasion in their answers for reasons of social pressure (Cairns, 1979).

\section{Reliability of the Interviewers and Coders}

Reliability between coders was checked by computing Cohen's kappa and percent agreements between coders for selected interviews which had been coded by both coders. These two methods of assessing reliability between coders are commonly used in research studies. However, there might have been influences on the interviewers and coders as individuals which would affect the reliability of their responses.

Interviewers might have felt personal biases towards individual subjects ("halos") or groups (stereotypes) (Cairns, 1979), and might not have been able to respond with equal enthusiasm to all subjects, thus influencing both the type and frequency of the codes which were generated by the interview.

Coders not only were aware of which interviewer had conducted each interview, but the coders had also acted as interviewers themselves. Because of these factors, coders were potentially biased in the coding of the interviews they themselves had conducted, by their recollections of what had occurred in these interviews.

The coders were another possible source of unreliability in that they were assumed to understand the 
theoretical background of the concepts they were coding, and to be able to detect these concepts in the interview transcripts (Cairns, 1979). Concepts not understood well by the coders would have less likelihood of being coded. Although random interviews were checked for interrater reliability (kappa), not all codes appeared in these particular interviews.

Reliability and Validity of the coding system

Yet another source affecting reliability could have been the coding system. The coding system for this research project was extensive, encompassing 31 codes for the older women workers and 30 codes for the younger women co-workers. This fact alone could have lowered the reliability of the coding system by imposing a cognitive load on the coders, who might have compensated by selecting a smaller number of codes which they felt comfortable in assigning.

The validity of the coding system might have been affected by very subtle distinctions between some of the codes (e.g., between PAYJUST and PSYPAY) which might have interfered with their proper detection by the coders. A similar fine distinction between codes led to the conclusion that IMPPRESS and IMPUP might not be mutually exclusive, and made it necessary to recode IMPPRESS to occur each time IMPUP had been coded. This realization affected the usefulness of IMPPRESS as an independent code for separate 
analysis, but emphasized the overlapping effects of work which were a concern of the study.

\section{Reliability of the codes}

Codes on which the coders reached or exceeded 60 percent agreement were included in the analysis, but still must be interpreted carefully (see Appendix $\mathrm{E}$ for codes with reliabilities not reaching 60 percent agreement between coders). A code like RESPECT, which was mentioned by 81 percent of the older women and reached 64 percent agreement based on 25 mentions of the code in the 10 interviews checked for reliability, can probably be considered reliable. On the other hand, a low frequency code like CONOVER2, which was mentioned by only 3 percent of the younger co-workers yet which reached 100 percent agreement based on 0 mentions in the reliability interviews, requires more caution in its interpretation. While the coders agreed completely that CONOVER2 was not present, we cannot be sure that they would have recognized the code in the interview material had it appeared.

The performance of a large number of statistical tests is known to increase the probability of finding significant results. Because this was an exploratory study, open to any codes which might arise in the data, all codes which met the reliability criterion of 60 percent agreement were subjected to statistical testing. 
of the 36 codes which were considered reliable, 5 (IMPEMOT, CHEAP, HELPNURT, HINDPHIL and PAYREL) had significant chi-square results. For individual chi-square tests, a conservative approach was taken by applying "Yates' correction" to each $2 \times 2$ matrix which had a cell frequency less than 5 (Ferguson, 1981). The small number of surviving codes may be explained by the low frequencies in some cells of the chi-square tests of independence, which made it more difficult to achieve significance.

\section{CONCLUSIONS}

After interviewing the older women, especially those in SCSEP, it is easy to agree with stentzel (1987) that "many older women, although working, are 'underemployed' in terms of their skill and wages" (p. 13). The rich and varied work histories which were reported in the interviews with the older women must have made it difficult for many of them to accept the lower status and wages which came with the SCSEP training program.

older workers who undergo training and are unable to find employment afterwards are known to be more upset and disappointed by unemployment than they were before undergoing training (Johnson, 1980). Many of the SCSEP workers had been in the job training program for over two years, and still had not found permanent jobs. The findings 
of this study point up the awareness in the older women workers in SCSEP who knew that they were providing cheap labor for their organizations while waiting for job opportunities that might never come.

older women who worked in FGP were "stipended volunteers," not job trainees, and although they were glad of their pay and benefits, they did not express as much anxiety about their futures.

Both groups of older women, those from the senior Community Service Employment Progrm and those from the Foster Grandparents Program, were in need of a way to adequately provide their own livelihoods. They were willing to work to provide for themselves, but the available jobs paid poorly.

In order to meet the needs of older working women such as those interviewed in this study, other investigators have made several suggestions for changes to existing social policy (Figart, 1988; AARP, 1986; Stentzel, 1987): 1) restructure existing jobs to create new ways for older women to move into jobs with more status and responsibility [this would be "re-skilling"---the reverse of the "de-skilling" trend reported by Braverman (1974)]; 2) improve compensation by re-evaluating work done by women and granting it comparable worth with work done by men (the older women in this study were trying to support themselves on half-time 
minimum wages) ; 3) fight age-related discrimination by pursuing affirmative action in hiring and promoting and by active enforcement of laws against discrimination (older women in this study reported instances of discrimination which they had experienced); and 4) expand the focus and funding of legislation for programs such as SCSEP to include the training of older women workers with incomes above the current poverty-level requirements for entry to the program (AARP, 1986).

This study of older women workers and their younger women co-workers demonstrated that there was a perceived impact of the older women's entry into the work force on the work of their younger co-workers. Relations between the two generations were seen to be cordial, with both negative and positive aspects of the relationship mentioned by the younger women co-workers. No significant relationship was found between the perceived impact of the older women's work on that of their younger co-workers and intergenerational relationships in the workplace.

\section{SUGGESTIONS FOR FUTURE RESEARCH}

Program type and the age of the older women were confounded in this study, with FGP employing women who were significantly older than those employed by SCSEP. Research has shown that differences in labor force participation 
occur in cohorts separated by as little as five years (Herz, 1988), so the age/program confound may well also be a cohort/program confound. Avoiding a confound between age and cohort is not possible in cross-sectional studies such as this; a longitudinal or time-lag design would be more successful in untangling these effects.

Researchers working with matched pairs of respondents should develop a protocol to ascertain that each younger coworker is actually the person with whom the older woman works most closely. Relying on verbal confirmation of this status can lead to uncertainty about the veracity of the report of the co-worker.

When studying older workers in part-time positions, future research on intergenerational relations in the workplace either should attempt to minimize the effect of volunteering or should make a comparison of groups of older women of the same age who work as paid employees and paid volunteers, to help separate out the effects of age. This would allow stronger statements to be made about similarities and differences between the two types of paid work.

Future research in the area of intergenerational relations should include studies of the labor force experiences of older women in a variety of occupations, and their intergenerational interactions with co-workers, 
clients, and management. older women who work with younger male co-workers should be studied with special attention to age and gender stereotyping and awareness of inequities. older women who work with younger women managers should be studied with regard to power relationships within gender in the workplace. One possibility is that younger women in a position of power might become mentors to older women; another possibility is that more overt conflicts might emerge.

A more structured interview technique would allow frequency counts of codes, rather than mere tabulation of presence or absence of a code in a given interview. These data would provide information on the intensity of a subject's concern with a theme. Additionally, by ensuring that the interview schedules for the intergenerational groups are parallel, data could be collected which will allow more comparisons to be made between groups. 
REFERENCES

ACTION. (1984). Impact evaluation of the Foster

Grandparent Program on the foster grandparents: Final

report. Washington, D. C.: Litigation Support Services.

AARP. (1986). Roundtable on older women in the work Force: Proceedings and Recommendations. Columbia, MD:

American Association of Retired Persons.

Ashbaugh, D. L. \& Fay, C. H. (1087). The threshold for aging in the workplace. Research on Aging, 9(3), 417427 .

Auerbach, D. A., \& Levenson, R. L. , Jr. (1977) . Second impressions: Attitude change in college students toward the elderly. The Gerontologist, 17, 362-366.

Best, F. (1979). The future of retirement and lifetime distribution of work. Aging and Work, $2,173-181$.

Braverman, H. (1974). Labor and monopoly capital. NY: Monthly Review Press.

Cairns, R. B. \& Green, J. A. (1979). How to assess personality and social patterns: Observations or ratings? In R. B. Cairns (Ed.), The analysis of social interactions: Methods, issues, and illustrations (pp. 209-226). Hillsdale, NJ: Lawrence Erlbaum Associates.

Cohen, J. (1960). A coefficient of agreement for nominal scales. Educational and Psychological Measurement, 20 , $7-20$.

Crawford, B. (1990, February). Opportunities knock: A new era unfolds for part-time workers. AARP Bulletin, 31(2), pp. 1, 12.

Curran, H. P. (1984). Less than full-time work: opportunity or exploitation? (Summary). Proceedings of the conference on Women, Work, and Age: Policy Challenges (p. 14). Ann Arbor, MI: Institute of Gerontology, University of Michigan. 
Deuterman, W. V., Jr., \& Brown, S. C. (1978, June) . Voluntary part-time workers: A growing part of the labor force. Monthly Labor Review, pp. 3-10.

Eagly, A. H., \& Steffen, V. J. (1986). Gender stereotypes, occupational roles, and beliefs about part-time employees. Psychology of Women Quarterly, 10, 252267 .

Eccles, J. S. \& Hoffman, L. W. (1984). Sex roles, socialization, and occupational behavior. In $\mathrm{H} . \mathrm{W}$. Stevenson \& A. E. Siegel (Eds.), Child development research and social policy, vol. 1 (pp. 367-420). Chicago: University of Chicago Press.

Feldberg, R. L, \& Glenn, E. N. (1983). Technology and work degradation: Effects of office automation on women clerical workers. In Rothschild, J., Machina ex dea, (pp. 59-78). New York: Pergamon Press.

Ferguson, G. A. (1981). Statistical analysis in psychology and education. New York: McGraw-Hill Book Company.

Figart, D. M. (1988). Economic status of women in the labor market and prospects for pay equity over the life cycle. Washington, D. C.: Women's Initiative and Policy Institute, American Association of Retired Persons (AARP).

Fleisher, D. (1981). Alternative work options for older workers: Part IV. Policy implications. Aging and Work, 4 , 153-160.

Graham, H. (1983). Caring: A labour of love. In Finch, J., \& Groves, D. (Eds). (pp. 13-30) . Labour of Love: Women, Work and Caring. London: Routledge and Kegan Paul.

Haefner, J. E. (1977). Sources of discrimination among employees: A survey investigation. Journal of Applied Psychology, 62, 265-270.

Harris, L., \& Associates, Inc. (1981). Aging in the eighties: America in transition. Washington, D. C.: National Council on Aging.

Herz, D. E. (1988, September). Employment characteristics of older women, 1987. Monthly Labor Review, pp. 3-11.

Hochschild, A. I. (1983). The managed heart. Berkeley, CA: University of California Press. 
House, J. S. (1981). Work stress and social support. Reading, MA: Addison-Wesley Publishing Company.

Jacobson, D. (1979). The social environment: A neglected dimension in the study of older workers' job performance. In H. Orimo, K. Shimada, M. Iriki, \& D. Maeda (Eds.), Recent Advances in Gerontology (pp. 377378). Amsterdam: Excerpta Medica.

Johnson, E. (1980). Growing old. New York: Holt, Rinehart and Winston.

Kahne, H. (1985). Not yet equal: Employment experience of older women and older men. International Journal of Aging and Human Development, $\underline{22}(1), 1-13$.

Kaplan, B. H. (1981). Alternative work options for older workers: Part III. The union and professional association view. Aging and Work, 4 , 146-152.

Marshall, R., \& Paulin, B. (1987). Employment and earnings of women: Historical perspective. In K. S. Koziara, M. H. Moskow, \& L. D. Tanner (Eds.), Working women: Past, present, future (pp.1-36). Washington, D. C.: The Bureau of National Affairs, Inc.

McConnell, S. R. (1981). Alternative work options for older workers: Part II. The managers' view. Aging and Work, 4, 81-87.

Muchinsky, P. M. (1978). Age and job facet satisfaction: A conceptual reconsideration. Aging and Work, $1,175-$ 179 .

Nieva, V. F. (1985). Work and family linkages. In L. Larwood, A. H. Stromberg, \& B. A. Gutek (Eds.), Women and work: An annual review, vol. 1 (pp. 162-190). Beverley Hills, CA: Sage.

Olson, L. (1982). 'Dynamic labor shortage' in the offing. Aging and Work, $\underline{5}, 15-21$.

Patton, M. Q. (1980). Qualitative evaluation methods. Beverley Hills, CA: Sage.

Rix, S. E. (1984). Older Women: The Economics of Aging. Washington, D. C.: Women's Research and Education Institute.

Root, L. S. (1985). Corporate programs for older workers. Aging, No. $351,12-16$. 
Saltz, R. S. (1971). Aging persons as child-care workers in a foster-grandparent program: Psychosocial effects and work performance. Aging and Human Development, 2 , 314-339.

Schindler-Rainman, E., \& Lippit, R. (1971). The volunteer community: Creative uses of human resources. Washington, D. C.: NTL Learning Resources.

Seidel, J. V., Kjolseth, R., \& Seymour, E. (1988). The Ethnograph: A User's Guide (Version 3.0) [computer program and manual]. Littleton, co: Qualis Research Associates.

Shaw, L. B. (1985). Older women at work. Washington, D. c.: Women's Research and Education Institute.

Shaw, L. B., \& Shaw, R. (1987). From midlife to retirement: The middle-aged woman worker. In $\mathrm{K}$. $\mathrm{S}$. Koziara, M. H. Moskow, \& L. D. Tanner (Eds.), Working women: Past, present, future (pp. 199-331). Washington, D. C.: The Bureau of National Affairs, Inc.

Soldo, B. J., \& Agree, E. M. (1988). America's elderly. Population Bulletin, $43(3), 1-53$.

Sparrow, P. R. (Autumn/Winter 1986). Job performance among older workers. Aging International, 13(4), pp. 5-6, 22 .

Stagner, R. (1985). Aging in industry. In J. E. Birren \& K. W. Schaie (Eds.), Handbook of the Psychology of Aging (pp. 789-817). New York: Van Nostrand Reinhold Company.

Stentzel, C. (1987). Women, Work and Age: A Report on older Women and Employment. Washington, D. C.: National Commission of Working Women of Wider opportunities for Women.

Stephens, R. (1989, December). New hurdles at work: Technology, rising health costs hurt older workers. AARP Bulletin, $\underline{30}(11), \mathrm{pp} .1,4,5$.

U. S. Department of Labor, Bureau of Labor Statistics. (1984). Employment and Earnings, 31(1), 164 .

Usher, C. (1981). Alternative work options for older workers: Part I. Employees' interest. Aging and Work, $\underline{4}, 74-80$. 
Veroff, J., Douvan, E., \& Kulka, R. A. (1981). The inner American: A self-portrait from 1957-1976. NY: Basic Books, Incorporated.

Voydanoff, P. (1987) . Work and family life. Newbury Park, $C A$ : Sage Publications, Inc. 
APPENDIX A

OLDER WOMEN WORKER INTERVIEW FORM 
Interview with older woman

I. Work setting

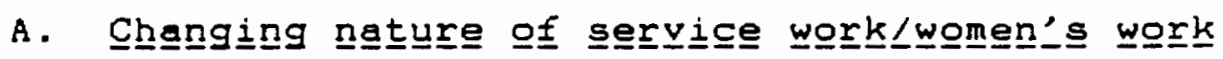

What do you do at _._._._. (name of organization)?

What kinds of things have you done in the past that have helped you or prepared you to do this kind of work?

Before you came there, how did the work you do now get done?

If you weren't at _..._-_. (name of organization), how wauld you imagine that the work that you do there would get done?

How do you think your being there has affected the work done by your younger co-workers?

How has their work changed since your arrival?

How do you think your co-workers feel about the work you do? About the use of ______s (name of program) at _...-.- (name of organization)?

How do you think the administration at (name of organization) benefits from the use of s (name of program)?

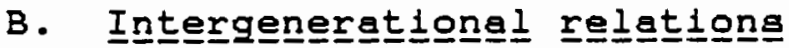

What kinds of things do you do there with your younger co-workers just for fun (e.g., go to lunch, coffee breaks)?

How often do you see your younger co-workers outside of work? Under what circumstances?

Do the _-___s (name of program) go to the staff parties at - (name of organization)? (If so, how often?)

Can you describe something that has happened with your younger co-workers that made you feel good? Feel bad? 
What kinds of problems or conflicts have you faced at your workplace?

What kinds of problems do you think come up sometimes between the _..._._s (name of program) and regular staff (e.g.) arguments or personality clashes)? (PROBES: Does an example come to mind? What do you think should be done about it? How would those changes come about?)

How do you feel about the pay or benefits you receive for working at organization)?

Overall, what do you think makes working at (name of organization) worthwhile (i.e., what makes you feel good about your work)?

II. Family

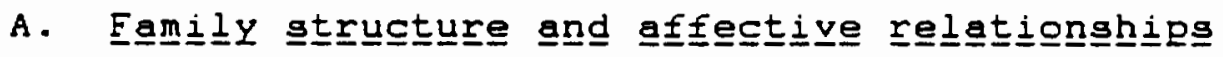

Can you tell me about your family (e.g., number of children, grandchildren, where they live)?

How would you describe your relationghip with your children now, at this point in your life? How do you get along with (target child)?

How often do you see or talk to (target child)? [PROBE re both visits and phone contacts with (target child). Get estimate of number of both per week, i.e., How often would that be per week?]

Who tends to initiate the visits or phone calls? What kinds of things, if any, do you feel comfortable talking with (target child) about? (PROBE for shifts over time, or as a function of older mother working/volunteering.)

In what ways are you like (target child)? In what ways are you unlike (target child)?

In what ways do you think your relationshipg with your children and grandchildren are similar to or different from other people your age [i.e., What have you noticed about your relationship with (target child) that seems similar to other people your age]? 
How do you imagine your relationship with (target child) might change as you get older? [If emphasis on theme of independence. PROBE: You are very independent, and the two of you lead relatively separate lives. What do you imagine it would be like for the two of you if you had a greater need for (target child) in the future?]

\section{B. Pattterns of a}

Are there ways that your children help you or you help them? Are there ways that (target child) helps you or you help her/him?

I have a list of different types of help that family members sometimes provide for each other. I'm going to ask you which of these kinds of help. if any, you provide to (target child) these days. Sometimes these things don't come immediately to mind, so take your time.

\section{* Help LIST 1}

Homemaking

Are there situations where you help (target child) with homemaking activities such as shopping, cleaning, preparing meals?

Maintenance

Are there situations where you help (target child) with yard work or by doing household repairs?

Income

Are there situations where you help (target child) by giving her/him food or goods needed to live on, or money?

Personal care

Are there situations where you help (target child) with personal care, such as dressing or grooming?

Home health care

Are there situations where you help (target child) when she/he is ill? 
Transportation

Do you help (target child) with

transportation, such as providing a means of getting to work, or visiting her/his friends, or taking her/him shopping or to church or doctors' appointments?

Social and recreational activities

Are there situations where you help (target child) with entertaining at home, or getting out for fun, such as accompanying her/him to special events or meetings?

Employment

Do you help (target child) with employment. such as finding a job or a market for goods or services?

Spiritual

Do you help (target child) with spiritual or religious activities?

Bureaucratic mediation

Are there situations where you help (target child) in dealing with government agencies or businesses, such as making phone calls or filling out forms?

Reading materials

Do you help (target child) by providing books, magazines, or pepers?

Enrichment

Are there situations where you help (target child) learn new hobbies, arts, crafts. or special interests?

Protection

Are there situations where you help (target child) protect against crime or danger, such as checking on her/his health or security?

Care of grandchild/great-grandchild

Do you help (target child) with the care of her/his child/grandchild?

Psychological support

Are there situations where you help (target child) by listening to problems, and by giving understanding and affection? 
Advice/information

What kinds of situations or issues might come up where (target child) would seek your advice or input?

Housing

Do you help (target child) by providing living quarters for her/him?

I've been asking you about the help you provide to (target child) now, at the current time. How have any of these kinds of help changed as time has gone by (i.e., what kinds of help do you provide now that you didn't in the past, or what kinds of help did you provide in the past that now you do not)?

Can you think of any changes which seem to be due to your working/volunteering?

How do you imagine these kinds of help you provide now might change in the future as you get older?

I've been asking you about kinds of help you provide for your daughter/son. How do you think working/volunteering has affected your relationship in genergl with (target child)? [PROBE: How has your work affected how (target child) sees you?]

I'm going to return to the list of different types of help that family members sometimes provide for each other, and ask you this time which, if any. (target child) provides to you.

\section{* HelP LIST 2}

Homemaking

Are there situations where (target child)

helps you with homemaking activities such as shopping, cleaning, preparing meals?

Maintenance

Are there situations where (target child)

helps you with yard work or by doing household repairs? 
Income

Are there situations where (target child)

helps you by giving you food or goods needed to live on, or money?

Personal care

Are there situations where (target child)

helps you with personal care, such as dressing or grooming?

Home health care

Are there situations where (target child)

helps you when you are ill?

Transportation

Does (target child) help you with

transportation, such as providing a means of

getting to work, or visiting your friends, or

taking you shopping or to church or doctors"

appointments?

Social and recreational activities

Are there situations where (target child)

helps you with entertaining at home, or getting out for fun, such as accompanying you to special events or meetings?

Employment

Does (target child) help you with employment, such as finding a job or a market for goods or services?

Spiritual

Does (target child) help you with spiritual or religious activities?

Bureaucratic mediation

Are there situations where (target child)

helps you in dealing with government agencies or businesses, such as making phone calls or filling out forms?

Reading materials

Does (target child) help you by providing books, magazines, or papers?

Enrichment

Are there situations where (target child) helps you learn new hobbies, arts, crafts, or special interests? 
Protection

Are there situations where (target child)

helps you protect against crime or danger, such as checking on your health or security?

Psychological support

Are there situations where (target child)

helps you by listening to problems, and by giving understanding and affection?

Advice/information

What kinds of situations or issues might come up where you would seek (target child's) advice or input?

Housing

Does (target child) help you by providing living quarters for you?

I've been asking you about the help your daughter/son provides to you now, at the current time. How have any of these kinds of help changed as time has gone by [i.e., what kinds of help does (target child) provide now that she/he didn't provide in the past, or what kinds of help did she/he provide in the past that now she/he does not provide]?

Can you think of any changes which seem to be due to your working/volunteering?

How do you imagine these kinds of help (target child) provides might change in the future, as you get older?

How do you think working/volunteering affects the amount of time you spend with your children or grandchildren? With (target child)?

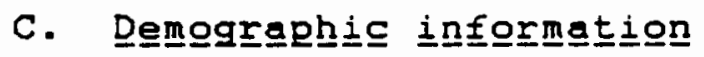

Before we stop, I have some questions to ask you that are usually included in research studies.

What is your date of birth?

Are you married? 
(If married) what kind of work does/did your husband do? (Does/did he work for someone else? Supervise people?)

(If not married) Separated or divorced? Widowed? (If so, how long?)

How many years of formal schooling have you had?

We have interviewed people who have been in and out of the workforce throughout their lives and others who have just recently entered the work world, as volunteers or as paid employees. Could you briefly tell me what your background has been in terms of paid work?

I've completed my questions. Is there anything else that you would like to say that we haven't covered or that you think would be helpful for us to know? 
APPENDIX B

YOUNGER WOMEN CO-WORKER INTERVIEW FORM 
Interview with Co-worker

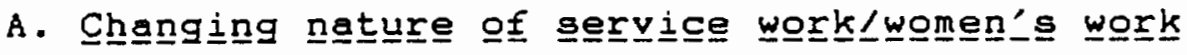

What kind of work do you do at _._._-_ (name of organization)?

How long have you been employed at _._._-_ (name of organization)?

How did you come to know _._._._. (name of older woman worker)?

What kinds of work does _._._. (name of older woman worker) do? How does what she does differ from the work that the regular gtaff do there?

Who used to do the work she does now? How has this assignment of work changed over time?

How has her presence affected your work? (If mention of experience or wisdom: What is it about the experience of older people that makes it valuable?)

B. Intergenengational relatationg

Describe some situations where she helped you carry out your work; hindered you in the work you do.

Are there things that the staff at (name of organization) does socially that includes the $s$ (name of program), e.g., lunch or coffee breaks, parties?

Are there things that you do socially with -..-- (name of older woman worker)?

In what situations would it not be appropriate to place older persons as workers/volunteers?

What concerns do other (relevant category of co-worker) who work with older persons have about the use of older persons in the workplace? 
What kinds of problems or conflicts have occurred with _...... (name of older woman worker) at - (name of organization)?

Do you think older people who do this type of work should be paid? How much (compared with other people in the setting)?

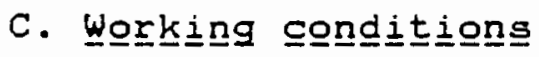

How do you think the administration at (name of organization) benefits from the use of older workers/volunteers?

In comparison to other jobs you've had, how do you feel about working at _..._._. (name of organization)?

How do you think the other staff feel about working there? Why?

What kind of staffing turnover is there? Why do people leave?

Are there things that you would like to see changed? How would those changes happen?

There are several questions that I'd like to ask you now that are sometimes included in studies about work. First, do you belong to any employee association? Why/why not?

What do you usually do after work?

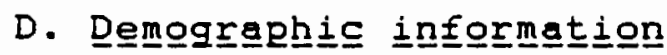

Before we stop, there are some final questions that I'd like to ask you that are usually included in research studies.

What is your date of birth?

Are you married?

(If married) Does your husband work outside of the home? What kind of work does/did he do? Does/did he work for someone else? Supervise other people?

(If not married) Separated or divorced? Never married? Widowed? (If so, how long?) 
How many years of formal schooling have you had?

I've completed my questions. Is there anything else that you would like to say that we haven't covered or that you think might be helpful for us to know? 


\section{APPENDIX C}

CODEBOOK FOR OLDER WOMAN WORKER 
CODEBOOK FOR OLDER WOMEN WORKERS ( 31 cOdes)

This Codebook was the training manual for coding older women worker interviews. Quotes from the coded interview data are inserted here to provide examples of the codes. The number of the interview from which quotes are drawn is given in parentheses following each example. Where no good example is coded, material from the training manual is used, and is identified as "training example."

codes are listed alphabetically and subsumed within conceptual categories. The percentage of respondents mentioning each code is given in parentheses following the code name. Codes marked by an asterisk reached a reliability of at least 60 percent agreement.

GOOD FEELINGS

ATTENT (Attention) (69\%). Receiving attention or affection from, feeling appreciated or supported by clients and/or co-workers. Includes pleasurable interactions with clients which don't include reference to service. Indicates a passive, receptive stance. (Code RESPECT if sentiment associated with specific contribution or valued behavior. Code IMPPRESS when work contribution associated with being needed.) 
For Christmas...they drew names and because I'm on a low income, they didn't even tell me about the exchange. But when they all unwrapped their things, they...gave me a package and it was a beautiful pink sweater. $(2-W-A)$

The appreciation they show when you have been gone a couple of days and come back. If you could just see it---be a mouse and watch it---...you would know how I feel. $(6-\mathrm{R}-\mathrm{A})$

When...they see you in the morning, you get a big smile and a big hello. And you know, they never just walk right by you like you were a piece of furniture. $(15-\mathrm{N}-\mathrm{A})$

* RESPECT (Respect) (81\%). Being respected for one's specific skill or knowledge in the workplace. Acknowledgement of ability to do a good job, think of new ideas, take initiative. Good feeling received from others is associated with contributions in the workplace. (Code SATPURCH when no relational component to this selfvaluation.)

Several times she sticks a little sticker note on my table: "That is good work, Grandma," or: "I can't get along without you." (4-R-A)

One man that works in the office, and I don't even know his name, but he was talking to (the supervisor) about when she was through with me, could he use me. And like (the supervisor) says, "Well, you know, that would be up to (the older woman worker), but we want to keep her as long as we can." (2-N-A)

On my evaluation she gave me "excellent" in almost every phase from attendance to comprehension of the job, and I got a very good report. Not that I'm bragging, but I'm proud of it. (9-W-A)

* SOLIDARITY (Solidarity) (3\%). Expressing solidarity with older woman/co-worker in their difficulties in the 
workplace. Supporting co-workers in gaining more respect or control. Includes element of struggling against forces or conditions which undermine workers. (Code BADCOORG for older women workers when solidarity expressed as feeling badly for a co-worker.)

Sometimes I have commented to them, when I have heard them stand up for themselves, which has been a reflection of brains and independence and goals orientation, and you know, sharing.... I always admire it when I see them taking hold, especially in regards to being women and meeting with hostile people in hostile situations. (9-R-A)

\section{BAD FEELINGS}

* AMBIVALENT (Ambivalent) (6\%). Feeling good, but somewhat ambivalent about receiving praise; being suspicious about the motivation for praise; sense of being manipulated by expressions of gratitude. Expressing ambivalence about social closeness with co-worker.

The children, with the problems they have to get too emotional with one person, you know, but they seem to like the fact that I am here.... They say, "Oh, Grandma,"---if you were out a day---"Where were you? We missed you." You know, even if they don't mean it, it sounds good. (11-R-A)

People go out of their way too much to tell me how happy they are to have me there, and they don't know what they would do without me. I am inclined to take it with a grain of salt. (18-N-A)

BADCLIENT (Bad-Client) (28\%). Concern with difficulties faced by clients in having needs met, inside or outside the work setting. 
At times, you know, you can't help but feel sorry for those kids.... They are not wanting to do this, but they react in a defensive way. (11-R-A)

You get involved in some of these case histories and you get lost in this poor child's life. Sometimes I come home and I am so depressed at the things that happened to these children. (16-N-A)

I remember the little boy that whispered, "My dad got shot in the stomach last night." A lot of things are really going on with these kids.... We have one little girl that looks very much like child abuse. I've been able to get information from her, about "What is that big round burn so deep in your cheek?" and things like that.... These kids.... So many of them have poor home lives, are badly neglected. Little girls come to school in the winter with little cotton dresses and no warm coats. Kids are hungry. (5-W-A)

BADCOORG (Bad-Co-worker-Organization) (19\%). Concern with problems faced by co-workers (including FGP and SCSEP workers) within the organization; difficulties with management; difficult working conditions; interpersonal conflicts among staff.

The people at SCSEP are a little bit demanding.... If our time sheets don't get in exactly when they think they should, they...bother (the agency secretary) about our time and little things. They are kind of demanding. $(2-\mathrm{H}-\mathrm{A})$

I tried to warn her, talk to her, but it didn't sink in until she got caught up with it. Yeah, I, it upsets me when you have to face that all the time... Not too often do they get fired from the center that I am in now. $(6-R-A)$

I think all teachers are overburdened. They have too large classrooms. I was amazed at the amount of bookkeeping that goes along with this. You not only do these things, but you have to keep records of them. $(13-\mathrm{R}-\mathrm{A})$ 
* BADINAD (Bad-Inadequate) (25\%). Concern with feeling inadequate; having difficulty keeping up, learning quickly, responding to demands in workplace. (Code BADCOORG also, when feelings of inadequacy or guilt also associated with co-worker having too much work to do.)

There has been a couple of times I have had to leave, and left her with a bunch of work. I felt bad about that. $(2-\mathrm{R}-\mathrm{A})$

I feel like possibly...I am not giving her as much help as she wants or needs. (13-R-A)

I am only there twenty hours, and sometimes it is like I am kind of spaced out. The things that have happened in the two or three days that I wasn't there... it takes me a few minutes to catch up on it when I go back to work. It's like I have slipped two or three cogs, you know, by not being there all the time. (15-N-A)

* BADSELF (Bad-Self) (16\%). Concern with being treated badly, disrespectfully, or being patronized by staff or clients; feeling singled out for bad treatment. (Code conco when bad feelings involve other people in the workplace.)

The people who work with the SCSEP offices, I feel like they are patting me on the head and taking me by the hand, and leading me around, and so I feel like their idea of a little old lady is---I don't know. But they don't act like I have good sense. (2-H-A)

The teacher was talking to the kids about courtesy and respect, because they got kind of rowdy... and I was towards the back of the class with (the aide)... and she was just kind of whispering, and (the teacher) says, "Looks like Grandma needs to join our circle and learn about courtesy and respect also." That hurts me deeply. (3-R-A) 


\section{CONFLICT}

* CONCHALL (Conflict-Challenge) (13\%). Conflict over lack of challenge in the job, lack of opportunity to learn new skills.

Once in a while, someone will come in (and say) that they don't feel that they're in the right job.... They want more computer training and they're not getting it. And they get a little bit unhappy about that. (9-W-A)

It gets kind of tiresome.... You can't broaden out very much.... Some days it's real interesting. Then it gets boring. (12-N-A)

Most of those jobs don't require that much training. They didn't really have to train me at doing that one thing, because I had already been a coordinator, you know, director of volunteers. And the rest of the things there don't take that much training. (17-N-A)

* conco (Conflict-Co-worker) (25\%). Conflict with coworkers, other regular staff; feelings of isolation, competition, hostility. Includes status or income differences when described as a personal conflict among the staff rather than an organizational problem. Represents the capacity to take the perspective of others. (Code BADSELF when bad feelings of others are directed toward the older woman herself.)

Between the staff they were nice to your face, then when your back was turned the staff talked about you. But those people aren't there any more. They quit before they got fired. (6-R-A)

He doesn't know how to be compassionate. He can be walking down the hall, and you can be going towards him, and if he doesn't want to say "good morning" to you, you might as well be a pillar in the middle of the hall. (8-R-A) 
I don't like gossip. Maybe I do gossip myself occasionally, I don't know.... If someone asks me, you either have to tell them what you've heard or you have to lie. But that is the source of all the problems and all the gossip, is the coffee breaks. They're tearing someone else apart.... I don't like to be part of it, so I don't get involved. $(9-\mathrm{N}-\mathrm{A})$

\section{* CONDEFEND (Conflict-Defend) ( $9 \%$ ). Conflict with}

defending limits of own work role; pressure from others in the workplace to work outside program guidelines, beyond assigned hours of work, or not take breaks. Includes mentions of deliberately working slowly or carefully following procedures as a means of dealing with role conflict in work setting. (Code CONOVER when desire to move beyond boundaries of job.)

It is not that I am unwilling to do work, but I wouldn't like to have... too much work pushed on me you know. And according to the Grandparents, we are not supposed to do janitor chores and office work and such. $(13-\mathrm{R}-\mathrm{A})$

Well, when I first went there they wanted me to do extra things, like take a bunch of children to another room, maybe, and give them a spelling test or something. But I'm not supposed to go out of the room, so I had to iron that out. And then they wanted me to do office work, run off papers, and laminate, and I'm not supposed to do that---that's for paid workers. $(3-D-A)$

CONOVER (Conflict-overstep) (16\%). Conflict with limitations of own work role in overstepping boundaries; frustration over constraints of job; desire to have more authority or responsibility. May include other people overstepping boundaries. (Code CONDEFEND when role conflict over defending boundaries.) 
You know, the kids cut and paste and paint and stuff like that, and just automatically as I go around I'd pick up the scraps of paper or the tinker toys that are on the floor and put them where they go. And a lot of the time she does not want me to do that, and several times she has asked me not to do it, and I don't do it for a while, and then I'll forget, and start tidying up as I go along. (5-W-A)

Some of (the children) go to therapy, and the room mothers usually put them in the wheelchairs because we are not supposed to lift over twenty pounds, unless you just kind of sneak it. $(19-\mathrm{N}-\mathrm{A})$

(The teacher) is afraid we're going to get in trouble because of the things I do. $(8-R-A)$

CONPROG (Conflict-Program) (50\%). Conflict with other FGP or SCSEP workers or administrators; feelings of competition or pettiness; seeing others in the program as bossy or stepping out of line in the work setting. Failure of program administrators to provide services. Use every time program is mentioned in this context.

She is the type of person that has an ego bigger than all get-out, and she can't help it, but she seems to monopolize every conversation, and everything. I let her reel on, because I think she is unhappy. She probably needs something. (11-R-A)

We have been coached in the money transactions that we were supposed to put on our time sheets, you know, and then, many times people do not understand that, and then there is kind of a flare up with that. (4-R-A)

We've got some little Grandmas over there that spend all their time on the phone telling (the FGP director) that we are breaking the rule, and it is so petty. $(19-\mathrm{N}-\mathrm{A})$

CONRESOLV (Conflict-Resolve) (16\%). When conflict arises with co-workers, older woman feels there are ways of 
resolving or addressing issues; sense of self-efficacy. Use wherever talk of conflict in the workplace being resolved.

If there's something that comes up I don't feel I can handle, I go to my supervisor or the teacher that's got the child. (l-D-A)

(The co-workers) are able to talk to us, and feel like that if they do have a problem, we can listen. (3-H-A)

I don't have any problems, because if something comes up and I can't handle it, I wait until (my supervisor) has a few minutes and go in and talk to her. (6-R-A)

\section{* CONSTRAIN (Conflict-Strain) (16\%) Conflict over}

physical or emotional strain of job; feeling tired or emotionally drained by work. Discussion of subjective response to a difficult situation.

It is kind of nice not to be there all day when you are doing phone work.... I was there one whole day and I got pretty tired when I was done. (17-N-A)

It wouldn't be possible, and it isn't because there would be too much pressure physically---I would have too much pressure emotionally. (13-R-A)

They want physical contact, especially at the first of the year. I sometimes have four and five kids all piled on my lap at the same time. Pretty soon my legs hurt so, and I couldn't figure out what was wrong with my legs. Well, I have real bad circulation anyway, and I thought, "Aha, those lap sitters." So I said, "No more lap sitting." (5-W-A)

\section{SOURCES OF SATISFACTION}

SATAFF (Satisfaction-Affect) (31\%). Positive affect, general good feeling associated with work; improved mental outlook as a result of work. Not working associated with negative affect. 
I would stay in it forever, I love it that much. They couldn't have put me in a better place than (this school). (4-R-A)

It is hard to explain. I go five days a week, and I'm there four hours, and (laughter) I just don't know how to explain it---I just feel marvelous there. (5-R-A)

I have worked over at their clinic, and I just enjoy working. (2-H-A)

* SATPAY (Satisfaction-Pay) (72\%). Economic reward of work in pay or benefits; any mention of income as a benefit of working. Includes prospects for future employment and income.

They give you your lunch-- $\$ 3.00$ to go to the cafeteria at the hospital---and then they buy your bus pass, and then we get $\$ 2.20$ an hour.... It sure does help to have that coming in. (19-N-A)

It is better than nothing. It does pay the utility bills. (10-R-A)

It's fine, it helps me. I'll be frank about it. It gives me about, oh, about $\$ 80.00$ every two weeks and then they furnish my gas and my meal---I'd say around $\$ 100.00$ every two weeks. $(1-D-A)$

SATPUR (Satisfaction-Purpose) (13\%). Sense of purpose provided by work; feeling of doing something worthwhile. Reduces self-occupation; takes mind off own problems. Refers to either general sense of purpose or overcoming self-absorption through work.

I think working is a life saver for me. I am not too well able to tell you in which way.... And I do know why people---older ladies---get so depressed: because they just sit and think about themselves. (4-R-A)

I volunteer for my joy of living. (13-R-A) 
I have thought about it and thought about it. I think it gives me satisfaction. You know, it just gives me a kind of a personal satisfaction. (19-N-A)

* SATPURCH (Satisfaction-Purpose-Challenge) (16\%).

specific sense of purpose in providing activity that is inherently interesting or challenging; pride in learning quickly. Includes cultural aspects of work (i.e., discovering different ways of life via clients or staff). (Code SATPURCH if learning emphasized.)

If I were working somewhere where I could use a computer, I would really loved to be trained in that. $(17-\mathrm{N}-\mathrm{A})$

There is so much to learn, a lot to learn about the appointments, and different studies, that they are in. $(18-\mathrm{N}-\mathrm{A})$

To work in an atmosphere like that is really nice because each teacher is different. And it's stimulating. I guess I hate to be bored. (3-D-A)

* SATPURSE (Satisfaction-Purpose-Serve) (59\%). Specific sense of purpose in providing service and doing work which is useful to clients, co-workers, or society in general. (Also coded in conceptual category "Good Feelings").

People come in and they're desperate for employment .... It's good to help somebody. (9-W-A)

I hope I am doing something beneficial with each one of the boys I have contact with, and that makes me feel good. (11-R-A)

You really feel like you are doing something, that you are accomplishing something and doing something for somebody else. (19-N-A)

SATSOCG (Satisfaction-Social-General) (25\%). General social contact at work; experience of being around other 
people. No mention of specific relationship. (Code SATPURCH when learning implied.)

I don't like being back in a hole by myself, I like people around. I don't want a big office, but I want some people contact. (16-N-A)

I like to be working with people that like to work with each other. $(8-W-A)$

I would be very unhappy sitting around the house not doing anything. I love to be around people. (2-N-A)

SATSOCS (Satisfaction-Social-Specific) (78\%). Specific social contact at work; social support received in interaction with co-workers and other staff (excluding clients). Specificity can be either in how relationship is described (by name or specific roles) or in the social interaction described (helping, working together). (Code RESPECT when emphasis on getting respect.)

(The teacher I work with) smokes and so do I. And we go off and have a cigarette together for ten minutes, and talk about what is going to happen tomorrow or the next day or something like that. $(8-R-A)$

(My co-workers) talk to me just like I'm one of them. They don't refer to me as, "...maybe we shouldn't say that, because (the older woman)'s around and she's older," or something. They just keep right on talking about whatever they are. It's never hush-hush. $(2-N-A)$

There is a nice feeling between the workers.... They are real nice and friendly.... Once a month, they have a nice big cake, and everybody celebrates their birthdays during that month. (19-N-A)

* $\quad$ SATSTRUC (Satisfaction-structure) (25\%). Structure provided by work; provides a place to go, something to do, way to keep busy; alternative to doing nothing. (Code 
SATPUR, SATPURSE, or SATPURCH when structure also associated with specific valued activities or commitments in the work setting.)

I am able to get out of the house, and into the mainstream of life... and that is worth money to me. $(15-\mathrm{N}-\mathrm{A})$

I felt pretty good about it, since I was beginning.... And since I can't make that much money anyway on Social security, I didn't feel bad about it. At least I had something to do. (1-H-A)

I am a lot better off since I've worked for Foster Grandparents than I was if I was sitting over at the old people's senior Citizen center in oregon City, listening to all their aches and pains. (1-R-A)

\section{INEQUITIES}

* CHEAP (Cheap) (59\%). Older worker is source of cheap labor for the organization; implies criticism of or bad feeling about low pay.

Oh, I imagine they love it because they're not paying our wages. They're getting all this fine help free for nothing. ( $(8-\mathrm{N}-\mathrm{A})$

Maybe to them that's all you're worth. But having been employed, and having received a top wage, naturally you're going to feel slighted. You're going to feel that you're working for the other person for nothing, you're receiving so little. Because if you've ever worked and had it all, it's kind of hard to work and have almost nothing. (9-N-A)

(The supervisor) is a good guy, but he's taken advantage of having free help to get a bunch of garbage stuff he had out of the way. (1-N-A)

DISCR (Discrimination) (13\%). Experience with or awareness of age discrimination in the workplace; includes 
denial of employment opportunities in hiring or promotion, poor treatment based on age.

I see that in looking for a job, that the older people are discriminated against. In my being laid off in a lot of my jobs, I feel it was because I was older.... And that is another thing, we are laid off just when we are going to be retired, so they don't have to pay us their retirement, and that bugs the crap out of me. $(3-\mathrm{H}-\mathrm{A})$

She didn't seem...prejudiced toward me, but when I heard they had hired someone very young, that had never done any of that sort of work, you know, it makes you wonder.... But how are you going to prove it? It would be very difficult. (10-R-A)

You don't have to put your age down on applications, but all they have to do is look at you when you walk in. It's very degrading when you go to apply for a job or they set you up for an interview and you go down there and there are 20 young ladies sitting there waiting for the same interview. You walk in, and they're very polite, and say to you, "Well, we'll let you know." And you know when you walk out you're not going to get the job. (2-N-A)

PAYJUST (Pay-Justification) (44\%). Low pay is

justified, either by making no critical inferences about the pay, or by emphasizing economic exchange value of training.

Includes responses which deny that inequalities exist for older worker in that setting.

If you haven't been out working for years and years--some of the people that come to the agency, they were homemakers, not like me that worked all their lives--they had to have some way of getting themselves back into the routine of working, and being out in the public. And so that's why the senior citizen thing is worthwhile. (12-N-A)

They are more than adequate with their time for holidays.... And for the ones of us that drive, they carry...collision insurance, and if we have any accidents going or coming from work, that is taken care 
of. They pay for that. So I don't know why anybody would hesitate...to work for them. (1-R-A)

When you get older you don't need as many fancy things and stuff as when you're younger.... Most of the people who are Grandparents now, are people that have lived through the Depression, you know, and hard times, so they can do with less than others. (5-N-A)

* PAYREL (Pay-Relative) (9\%). Older worker not paid well relative to other workers in setting.

Well, the wages, you see, are not balanced. Because if they had to hire...people that work temporarily---they get $\$ 6.00-$ some an hour and we only get basic wage. But we're doing the same thing they're doing, so see--that's really not quite balanced. (12-N-A)

I get paid through senior employment which is minimum wage, and, oh yeah, they get paid a lot more. (2-N-A)

* PSYPAY (Psychic-Pay) ( $9 \%$ ). Low pay is justified by emphasizing "psychic pay," or inherent gratification in the work; intangible benefits offset low pay.

I think more people should volunteer (to be of service to others). (training example)

We get a lot of things back from this program. (training example)

\section{IMPACT}

\section{* IMPEMOT (Impact-Emotional) (43\%). Older woman's} presence contributes to shift in emotional division of labor (i.e., discipline and limit-setting versus nurturance and affection). Older woman takes over the nurturant component of emotional labor, allowing co-worker to be more involved in disciplinary activity. 
I have kids piled on me. They want physical contact, especially at the first of the year. I sometimes have four and five kids all piled on my lap at the same time.... And they really want that contact, so, I, there's no way a teacher can do that. Absolutely not. $(5-W-A)$

I listen to the kids. The kids tell me a lot they wouldn't tell the teacher. They have a good teacher, but there's no way they can get in through the mob to tell a teacher.... one little girl was sitting beside me one day, at a time when she wasn't supposed to be talking, and she leaned over and whispered and said, "My mom gets to go to court today and then she's going to go to jail. I don't know who's going to come and get me this evening." ... A lot of things are really going on with these kids, that wouldn't come out if there wasn't just somebody sitting there available to listen. $(5-W-A)$

* IMPPRESS (Impact-Pressure) (88\%). Older woman worker reduces pressure or overload on co-worker by allowing coworker to do more of the same type of work. No mention of allowing co-worker to do different types of tasks. Coded wherever IMPUP occurred.

The work I do means somebody else doesn't have to do it. $(9-R-A)$

They do the same type of work all the time, it just makes them more free to do more of it. (7-R-A)

She had this meeting to go to in salem and I had to get out the press release.... It was already a day late, so it would have been two days late if I hadn't been there to do it. $(16-\mathrm{N}-\mathrm{A})$

* IMPUP (Impact-Upgrade) (44\%). Older woman upgrades coworker's work by taking over lower level tasks, freeing coworker to do more important work.

They would have to do all the things I do for them, which would...take them away from the kids. This way they have more time to spend with the kids teaching them Montessori methods. (3-R-A) 
They have been able to concentrate more on their business and not worry about what I am doing.... That leaves them open to spend their time with the people they (already) have. (3-H-A)

It helps her by getting some of the monotonous routine work done. That frees her to do things that only she can do. (16-N-A) 


\section{APPENDIX D}

CODEBOOK FOR YOUNGER WOMAN CO-WORKER 
CODEBOOK FOR YOUNGER WOMEN CO-WORKERS (30 cOdeS)

This Codebook was the training manual for coding younger women co-worker interviews. Quotes from the coded interview data are inserted here to provide examples of the codes. The number of the interview from which quotes are drawn is given in parentheses following each example.

Codes are listed alphabetically and subsumed within conceptual categories. The percentage of respondents mentioning each code is given in parentheses following the code name. Codes marked by an asterisk reached a reliability of at least 60 percent agreement.

HELP

* $\quad$ HELPNURT (Help-Nurturant) (47\%). Provides a nurturant function in relation to clients, or creates a family atmosphere in the work setting. Direct attention, rather than attention mediated by a task.

She has a rocking chair,... and she puts the kids around in a circle, in their wheelchairs and stuff and she reads them stories. She is about the only one that does that, too. (19-N-C)

Here they get their one-to-one, or a chance to cool down with somebody who will listen to them. (1-R-C)

If a child is having a hard morning, she will comfort them. She will kind of pick up the loose ends for us.... She will give special attention to a child who 
is having a difficult day or needs help getting started with the work. $(3-R-C)$

* $\quad$ HELPSUP (Help-Support) (50\%). Provides emotional

support or advice to co-worker or other staff; older woman is an ally.

It makes my day when she is there. I don't feel real high-strung when she is there. When she is not there, it is a kind of a depressing day. (19-N-C)

Sometimes if I am in doubt about a situation,...then I will ask her for feedback and she will give me insight--how she might have handled it. I think we complement each other very well, very well. (15-N-C)

I can walk into a room and she knows what my mood is--which I can cover pretty well---and she is, she is very perceptive. $(8-R-C)$

The afternoons were a nightmare at first,... and just having her there was just kind of a moral support to me.... I wasn't alone in that classroom with those 25 kids. $(3-D-C)$

* HELPTECH (Help-Technical) (97\%). Provides technical

assistance in carrying out tasks in the workplace; includes office work and direct service to clients.

Before I had (a Foster Grandmother to work with), I could see something happening out of the corner of my eye, but if I am busy with this child, I can't reach that child. When she is here in the room, I can usually catch her eye...or nod my head.... She is quick to spot what is happening.... What she does is go over and put them back on task, before they have time to throw a spit wad, or kick somebody. $(1-\mathrm{R}-\mathrm{C})$

We're so limited with these clients because some we can't take out in public. Their behavior is what they call socially non-acceptable, but like she took some clients the other day to the Rose Festival and that was really neat. $(2-\mathrm{N}-\mathrm{C})$

She generally does telephone recruiting, either calling people, and making appointments for them, screening them on the phone,...or she takes incoming calls, 
answers questions, also makes appointments for them, takes telephone calls off the recorder. She will also do little bits of paper work in the office, crosschecking names with appointments and times. (17-N-C)

She is working in our office right now in developing data bases for cooperator lists, and updating all of our cooperator files, and assisting my field staff in a comprehensive follow-up program for all of our cooperators in Multnomah county. Those are her major tasks. Secondary tasks (are) to assist with general typing, filing, reception-type work. (3-H-C)

She originally assisted (a regular worker) with the case bank, but now she is writing reports and doing basically the same kind of work he was doing. (9-R-C)

* HINDACCOM (Hinder-Accommodate) (44\%). Is a hindrance

to or creates special demands on the co-worker, who feels obligated to accommodate or adapt to special needs of older woman.

It takes me away from my work in order to train those people to get where they work on their own. But looking at the long range scope, that doesn't really play into effect, because it only takes me away for a certain period of time. $(9-\mathrm{N}-\mathrm{C})$

It's kind of like two steps forward and one step back, and that definitively, that back step---but it was worth the exchange with that. $(9-W-C)$

She said the learning process takes a little longer, and I have accepted that to be true, and I've been $a$ bit more patient. I hope I have learned to be more accommodating to any special needs of the older workers. $(12-\mathrm{N}-\mathrm{C})$

HINDER

CONOVER (Conflict-Overstep) (16\%). Oversteps boundaries of job or limits of authority in work role. Includes perception that older woman is frustrated by 
constraints of job, desires to have more authority or responsibility. (Code HINDPHIL when referral to problem in how to carry out work.)

I don't know if she really understood that I was supposed to tell her what to do. (6-R-C)

Every once in a while she will slide her hours a little bit longer than we are supposed to, she will start coming in a little bit earlier. (8-R-C)

She wanted to do more than she was trained to do, and what she was doing had nothing to do with it. (1-H-C)

* HINDAUTH (Hinder-Authority) (9\%). Does not project authority; is unable to handle situations which require discipline or behavioral intervention.

There are some volunteers I would not accept into my classroom. Because they would not be able to take the kinds of children I have in my classroom. (8-R-C)

She would usually work with about eight kids, so it wasn't too bad for her as far as numbers. I never wanted her to have too many more because it was hard for her to control.... She would just kind of sit there, and they would do things that they would never do. They wouldn't do that if I was sitting there with them. $(3-D-C)$

* HINDINSEC (Hinder-Insecure) (28\%). Is insecure, uncertain; lacks confidence. Doesn't have confidence to learn, or is limited by situational factors. May be component of empathy.

When she first came she was unsure of what her role was and I was unsure of what her role was. $(1-R-C)$

She was a little angry,... you know, because she is naturally anxious to do a good job. (10-R-C)

She beats up on herself, really a lot, if she makes a mistake. $(9-W-C)$ 
* HINDPHIL (Hinder-Philosophy) (19\%). Does not

understand philosophy of agency; works in a way which conflicts with agency goals.

We needed to tell her that it is okay for her not to wait so long to pick up the babies if they are on the floor and they are crying. $(5-\mathrm{R}-\mathrm{C})$

When one of the children is kind of fussy, usually I try to make things more quiet to calm the children down, but she is kind of a hyper type, hyperactive person. She will turn the music up, start the music box, turn the TV up and talks and talks and talks. $(7-\mathrm{R}-\mathrm{C})$

You know, these kids don't really have very good table manners. And they will often eat with their fingers or they will eat something and if they don't like it, they will just spit it out on their plate. She would oftentimes make comments about that, and it is not that she made the comment, but how it was said. (11-R-C)

* HINDPHYS (Hinder-Physical) (9\%). Is physically slow, incapacitated, prone to illness; references to impairment of senses (e.g., hearing, eyesight).

Our principal has been very concerned about the problem, and her ability to walk and the fear of falling. $(8-R-C)$

No, she really doesn't work with the kids. I think with her hearing problem it is hard to hear them. $(4-\mathrm{R}-\mathrm{C})$

* HINDRIG (Hinder-Rigid) (6\%). Is rigid, resists change, does not want to learn new tasks or new philosophy of work.

She is very opinionated, and if somebody is not doing things the way she thinks, and it is really bothering her, she will say something. $(8-R-C)$

(The older woman worker) is a by-the-book person, and if calls are supposed to come in a certain way, she'll take them only that way. Not willing to deviate at all from the instructions that were sent down to her.... We had a person come in, and she wouldn't talk to him. 
But he came back and got on the phone, and that was okay. (12-N-C)

* HINDSLOW (Hinder-Slow) ( $9 \%$ ). Is slow, passive, lacks initiative or ability to respond. Seen as a limitation not motivated by resistance to change.

I think (a regular worker) mentioned a couple of times that she wasn't really grasping how to write a report. $(9-R-C)$

As far as problems go, I wouldn't call them problems--just concerns with learning the information. $(17-\mathrm{N}-\mathrm{C})$

\section{POSITIVE}

POSDEPEND (Positive-Dependabie) (28\%). Older persons are dependable, hard-working, reliable, conscientious, responsible. Refers to ability to act.

Personally, I think older people are very dependable, a lot more than...a lot of the younger people---summer youth. It has been really hard for those people to show up.... They are out late the night before, and... you know what I am saying. A lot of times the older worker will show up on time---not as much

absenteeism. (12-N-C)

Mostly, the older ladies have done a good job. They work alone and they are careful. We don't have to go back and check everything they do, like we do with some of the other ones. $(16-\mathrm{N}-\mathrm{C})$

I also think they tend to be real dedicated. They don't call in sick real often. They are real dedicated to finish their job that they started. (18-N-C)

* POSEMOT (Positive-Emotional) (34\%). Older persons have positive emotional characteristics which make them pleasant to be around. Refers to calmness or emotional receptiveness. 
I think it's nice working with older people, or I just enjoy working with older people. They seem easier to get along with, not sort of petty, or any of that, so I think it's great. $(9-\mathrm{N}-\mathrm{C})$

They bring a real calming influence to the clinic, because they tend not to be real emotional, as far as they don't get upset easily. They tend to be more steady in their attitude and even-tempered. $(18-\mathrm{N}-\mathrm{C})$

* POSEXPER (Positive-Experience) (47\%). Older persons have had important life experiences or job-related experiences that benefit others in the workplace. Includes references to wisdom.

Older is perceived as more experiences and--knowledgeable, more trustworthy. So I would say instead of a concern, there would probably be some benefits in being older in this line of work. $(3-\mathrm{H}-\mathrm{C})$

Their experiences, things they share that they have gone through, Iife experiences---how can you rate that in monetary (value)? But that is what she does, you know. She shares a part of herself. (1-D-C)

I think it's the older you are, the more experiences you've had, the wiser you become. And just for them to share that with me is a good experience, because then I can sort of base what I do on the experiences that other people have had, and I think that makes me a little more wise. $(9-\mathrm{N}-\mathrm{C})$

NEGATIVE

* NEGMENT (Negative-Mental) (44\%). Older persons are slow mentally, rigid, insecure, childlike, lack initiative, have difficulty learning complex or technical tasks. (Code HINDACCOM also when co-worker expresses desire to accommodate older workers. Code "Hinder" categories if reference is to a specific older woman worker.) 
A lot of times they will tend to wander mentally, and they couldn't stick with more responsibilities. $(3-\mathrm{R}-\mathrm{C})$

I think we've had to work a little harder with the seniors--be a little more repetitive, give them a little more time, than I've had with younger people I have worked with over the years. $(12-\mathrm{N}-\mathrm{C})$

We don't even let them get the children's trays off the carts, because some of them might get the wrong tray. Things like have even happened in the room, where they grabbed the wrong bottle, or something---wrong bottle to give to the child---so we have to make sure that they get the right tray and the right bottle and everything. $(7-R-C)$

* NEGPHYS (Negative-Physical) (44\%). Older persons are physically slow, more prone to illness, likely to have impaired senses (e.g., hearing, eyesight). (Code "Hinder" categories if reference is to a specific older woman worker.)

I think it depends on their physical well-being. If it is poor, I think any lifting situation, like working in the special ed room.... Sometimes there is a lot of lifting going on, because you need to, (if) some child is throwing a tantrum or doing something. So you need to lift them up---or hold them down. (13-R-C)

We have seniors who have great difficulty with the phones. Some of them can't (tell what is going on) visually. It's difficult to distinguish between a light that's on hold and one incoming---they blink at a different rate but it is not easy to see. And actually, just being speedy enough to get rid of a call in time. Most of our seniors don't do calls. They're not comfortable enough, or good at it. (12-N-C)

Sometimes they worry about, um, falling down, or something. We had a couple of them fall, and some of them have high blood pressure and stuff like that, nothing real major. (19-N-C) 
NEGSTRESS (Negative-Stress) (19\%). Older persons in general don't tolerate stress or pressure well; have general difficulty keeping up with pace of work. Focus on particular situations in workplace that are hard to handle. (More general than NEGMENT or NEGPHYS). (Code "Hinder" categories if reference is to a specific older woman worker.)

I think that in general they would become flustered and frustrated if they were given more work, more tasks than they could handle. $(3-R-C)$

There is too much stress and they can't deal with it. And they shouldn't be expected to deal with it. That is a definite problem with workers who have been working for a long time, who are getting older--middle-aged women going through menopause, what not--they are a pain, pardon me, to work with when they are under heavy stress. (10-R-C)

Well, some of my co-workers have said...that sometimes Grandmothers will get in little tiffs with each other... and that makes it a little hard.... some have said that during a panic situation or something like that, that the Grandmothers will panic.... I know during the fire drill, when there was real fire once, one of the Grandmothers was just about to faint, and it kind of got in the way of getting the kids ready for evacuation. $(8-W-C)$

CONFLICT

* BADORG (Bad-organization) (69\%). Concern with problems within the organization; difficulties with management; difficult working conditions; interpersonal conflicts among staff.

You have to keep giving and giving and giving, without any kind of reward for that. This is the only organization I have worked in where during the holidays 
they said we could take off a half a day on Christmas Eve, then we didn't get that half a day. We either (have) to take vacation or take it without pay, or take out half a "float" day. I mean, they give us nothing. They give us the minimal amount of holidays. (2-H-C)

One teacher suggested a retreat---go away to the beach--and people just laughed at her.... You kind of get slapped on the hand for trying anything positive. $(3-D-C)$

I would like to see the administration respond to the physical deterioration of this facility. Because in the past three years, we have gone from three housekeepers to one. $(3-R-C)$

* CONCHALL (Conflict-Challenge) (13\%). Conflict over lack of challenge in the job, lack of opportunity to learn new skills.

There are times that I wish I could deal more in a counseling situation. $(1-R-C)$

At this point, it is getting kind of boring. I never thought it would get boring, but I mean,...I have seen criminals for five years now. I always thought... "Criminals will always be exciting," because new crimes and this and that, but I think this is kind of boring. $(9-\mathrm{R}-\mathrm{C})$

We lose a lot of people because their talents are not used. I have been threatening to quit almost since I started, because they don't use my talents. (1-H-C)

* CONOVER2 (Conflict-Overstep-2) (3\%). Conflict with

limitations of own work role in overstepping boundaries;

frustration over constraints of job; desire to have more authority or responsibility.

I guess maybe I would like to be working with more of the students than $I$ am right now. (1-D-C) 
* CONRESOLV (Conflict-Resolve) (19\%). When conflict arises with other co-workers or older woman, co-worker feels there are ways of resolving or addressing issues.

If there is a problem, find out what it is as quickly as you can and get it dealt with. Whether it is me talking with her, and then talking with the other person, or getting the two of them to talk together--which is what I eventually try to do---we always have. $(8-\mathrm{R}-\mathrm{C})$

Yeah, if you have enough back-up, with your coworkers,...they will do something. (8-W-C)

We come up with our complaints, our concerns, our reasons why we are not happy, and then talk to those, in a group situation with our supervisor. (1-H-C)

* CONSTRAIN (Conflict-Strain) ( $34 \%$ ). Conflict over physical or emotional strain of job; feeling tired or emotionally drained by work. Includes references to stress or burnout.

There does seem to be quite a bit of pressure.... You work if it means you work two hours past your schedule. you do it just to get the job done. And hope you get some time off. $(17-\mathrm{N}-\mathrm{C})$

I find myself sometimes coming from work extremely tense. $(9-R-C)$

Part of it, I feel, is burnout for some of them.... It's like they've got this full-time job with kids all day long that need you nonstop, ... and then you come home to kids that need you. $(3-D-C)$

\section{INEQUITIES}

* CHEAP (Cheap) (47\%). Older worker is source of cheap labor for the organization; implies criticism of or bad feeling about low pay. 
Well, I know how much Grandma gets, and I think it is terrible. I think she should be given at least minimum wage. $(3-R-C)$

You get twice the work done for half the money, and basically it is a write-off to the company, and they end up darn near paying nothing because they're employing the seniors. $(1-\mathrm{H}-\mathrm{C})$

DISCR (Discrimination) (9\%). Experience with or awareness of age discrimination in the workplace; includes denial of employment opportunities in hiring or promotion, poor treatment based on age.

Just the fact that they are not being used to their full potential and there isn't a position that will usually hire them that is in their age range.... Just because of their age doesn't mean they can't do it. $(1-\mathrm{H}-\mathrm{C})$

PAYJUST (Pay-Justification) (19\%). Low pay is justified, either by making no critical inferences about the pay, or by emphasizing economic exchange value of training. Includes responses which deny that inequalities exist for older worker in that setting.

I see nothing wrong with it. They pay the minimum wage I am sure. All of them are retired. Retirement money is not that big---maybe this is the gravy for her. $(I-R-C)$

Well, I think they should be reimbursed for something. They have to have gas to get back and forth. (9-R-C)

They do get a free lunch, that's just something. $(3-D-C)$

* PAYREL (Pay-Relative) (50\%). Older worker not paid well relative to other workers in setting.

I feel real bad that she does a lot of the same stuff that I do and I probably get almost triple the wages that she does. $(2-\mathrm{R}-\mathrm{C})$ 
If they're doing the same job I'm doing, they should be paid the same amount of money that I'm getting paid. $(9-\mathrm{N}-\mathrm{C})$

Their time is valuable just like the rest of our time. $(1-D-C)$

* PSYPAY (Psychic-Pay) (13\%). Low pay is justified by emphasizing "psychic pay," or inherent gratification in the work; intangible benefits offset low pay.

Different people do it for different reasons. Maybe they don't really need that, maybe they just want it for their own, to get out of the house, to be around people. (3-D-C)

SOLIDARITY (Solidarity) (19\%). Expressing solidarity with older woman/co-worker in their difficulties in the workplace. Supporting co-workers in gaining more respect or control. Includes element of struggling against forces or conditions which undermine workers.

A lot of times they will hire from the outside, instead of promoting the people which are in the departments, which I think is a disservice to those employees that have worked so hard. If they want to be able to work...upward in the organization, I think they should be given the chance to do that, and given the training and the skills and the education to be able to do that. $(2-\mathrm{H}-\mathrm{C})$

I would like to see the staff have a little more power... in what happens to their treatment kids. $(11-\mathrm{R}-\mathrm{C})$

There's another teacher coming from another school... and she's a real fighter, so she's inspired me a bit.... She sort of refuses to teach there without those things that she finds really necessary.... I think she may get some things changed... We'll have a team. $(5-W-C)$ 
IMPACT

* IMPPRESS (Impact-Pressure) (100\%). Older woman worker reduces pressure or overload on co-worker by allowing coworker to do more of the same type of work. No mention of allowing co-worker to do different types of tasks. Coded wherever IMPUP occurred.

She does actually part of my job. We have increased outpatient flow and we can't increase our staff with the county budget, so she is just helping me with part of my work. (2-R-C)

We miss her on Fridays when she is not here, because then we all have to fill in and do it... $(8-\mathrm{N}-\mathrm{C})$

She's like an extra hand, and with first-graders you need an extra hand, so it has helped tremendously. $(5-\mathrm{N}-\mathrm{C})$

I don't really see how we could do the job we do without our seniors.... If they were all to vanish tomorrow, we could still carry on our programs, but it wouldn't be with the same level of attention and service that we are able to give now. (12-N-C)

* IMPUP (Impact-Upgrade) (66\%). Older woman upgrades coworker's work by taking over lower level tasks, freeing coworker to do more important work.

Every day I ask her to do the paper work for me that I don't have time for. She is willing to cut paper for me, and take care of child in the bathroom who has wet his pants. I can't leave a situation, so she will pick up the loose ends and help out in that way. (3-R-C)

I can give her the assignment and ten minutes later she has it done. And she brings it back to me and it makes me look efficient, you know. I can call the supervisors back and say, "This is the information I have for you." $(2-\mathrm{H}-\mathrm{C})$

By her doing the administrative end of things, like the data base,.... can provide services I couldn't provide 
before to a wider number of people than I previously provided for. It has exponentially increased the availability of services from this office. (3-H-C) 


\section{APPENDIX E}

CODES NOT REACHING RELIABILITY CRITERION 
TABLE XI

PERCENTAGE OF OLDER WOMEN WORKERS (OWW)

AND YOUNGER WOMEN CO-WORKERS (COW)

MENTIONING CODES NOT REACHING 60 PERCENT AGREEMENT

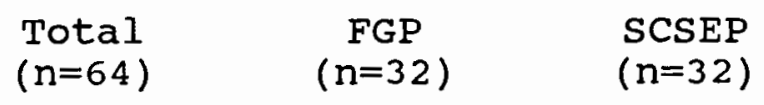

code OWW COW OWW COW OWW COW

Good Feelings

ATTENT

68

94

44

Bad Feelings

BADCLIENT

BADCOORG
28

19
50

19
6

19

Conflict

CONOVER

16

CONPROG

50

16

31

63

CONRESOLV ${ }^{1} \quad 16$

16

25

0

6

38

25

Sources of Satisfaction

$\begin{array}{lllr}\text { SATAFF } & 31 & 50 & 13 \\ \text { SATPUR } & 13 & 25 & 0 \\ \text { SATSOCG } & 25 & 19 & 31 \\ \text { SATSOCS } & 78 & 88 & 69\end{array}$

Positive

POSDEPEND

28

13

44

Negative

NEGSTRESS

19

19

19

Inequities

$\begin{array}{lrrrrrr}\text { DISCR } & 13 & 9 & 0 & 0 & 25 & 19 \\ \text { PAYJUST } & 44 & 19 & 63 & 31 & 25 & 6 \\ \text { SOLIDARITY }^{2} & - & 19 & - & 19 & - & 19\end{array}$


Notes: ${ }^{1}$ CONRESOLV reached greater than 60 percent agreement for the Younger Women Co-Workers.

${ }^{2}$ SOLIDARITY reached greater than 60 percent agreement for the older Women Workers. 
TABLE XII

RELIABILITY: PERCENT AGREEMENT OF CODERS FOR CODES NOT REACHING 60 PERCENT AGREEMENT (OLDER WOMEN WORKERS AND, YOUNGER WOMEN CO-WORKERS) ${ }^{1}$

\begin{tabular}{cccccc} 
& \multicolumn{2}{c}{$\begin{array}{c}\text { Older Women } \\
\text { Workers }\end{array}$} & & \multicolumn{2}{c}{$\begin{array}{c}\text { Younger Women } \\
\text { Workers }\end{array}$} \\
\cline { 2 - 3 } \cline { 5 - 6 } & $\%$ & $n^{2}$ & & $\%$ & $n^{2}$ \\
\hline
\end{tabular}

Good Feelings

ATTENT

Bad Feelings

BADCLIENT

BADCOORG

Conflict

CONOVER

CONPROG

CONRESOLV ${ }^{3}$
43

14

$50 \quad 10$

03

Sources of Satisfaction

$\begin{array}{lrr}\text { SATAFF } & 22 & 9 \\ \text { SATPUR } & 0 & 1 \\ \text { SATSOCG } & 50 & 6 \\ \text { SATSOCS } & 58 & 19\end{array}$

Positive

POSDEPEND

50

6

Negative

NEGSTRESS

50

4

Inequities

DISCR

PAYJUST

SOLIDARITY ${ }^{4}$
50

36
2

11
33

3

12

1

6 
Notes: ${ }^{1}$ Analysis based on 10 (for OWW) and 11 (for cow) randomly-selected interviews checked for reliability.

2 Number of mentions of code upon which coders agreed.

${ }^{3}$ CONRESOLV reached greater than 60 percent agreement for the Younger Women CoWorkers.

${ }^{4}$ SOIIDARITY reached greater than 60 percent agreement for the older women Workers. 
APPENDIX F

CONSENT FORMS 


\section{INFORMED CONSENT-- OLDER WOMAN}

I, a research project conducted by the Department of Psychology at Portland State University called "Service work by Older Women: Effects on Intergenerational Relations in the Workplace and Family."

I understand that I will be asked questions about my work as $a(n) \ldots \ldots$, and how it has affected the relationships I have with my co-workers and with my family. In addition, I have been asked to identify a co-worker and a child so that they, too, may be interviewed. It has been explained to me that the purpose of the study is to learn more about how paid or volunteer work affects the lives of older women, particularly their relations with their children and the younger women with whom they work.

I understand that the interview will take approximately 1 to 1 1/2 hours of my time, and will be tape-recorded. I realize that I am free at any point to refuse to answer any particular question. It has been explained to me that everything I say during the interview will be kept entirely confidential.

I may not receive any direct benefit from participating in this study, but my participation may help to increase knowledge which may benefit others in the future.

has offered to answer any

questions I may have about the study and what is expected of me, as long as this does not involve revealing confidential information from anyone else interviewed.

I understand that I am free to withdraw from participation in this study at any time without jeopardizing my relationship with portiand state University or

I have read the foregoing information.

Dete Signature

If you experience problems that are the result of your participation in this study, please contact Bernard Ross, Office of Graduate Studies and Research, 345 Cramer Hall, Portland State University, telephone 4643423 . 
I, for a research project conducted by the Department of Psychology at Portland State University called "Service Work by Older Women: Effects on Intergenerational Relations in the workplace and Family."

I understand that I will be asked questions about how the presence of has affected my own work and that of other paid staff here. I will also be asked about the relationships I and other staff have with explained to me that the purpose of the study is to learn more about how paid or volunteer work affects the lives of older women, particularly their relations with their children and the younger women with whom they work.

I understand that the interview will take approximately one-half hour of my time and will be tape-recorded. I realize that $I$ am free at any time to refuse to answer any particular question. It has been explained to me that everything I say during the interview will be kept entirely confidential.

I may not receive any direct benefit from participating in this study, but my participation may help to increase knowledge which may benefit others in the future.

has offered to answer any

questions I may have about the study and what is expected of me, as long as this does not involve revealing confidential information from anyone else interviewed.

I understand that I am free to withdraw from participation in this study at any time without jeopardizing my relationship with Portland State University.

I have read the foregoing information.

Date Signature

If you experience problems that are the result of your participation in this study, please contact Bernard Ross, Office of Graduate Studies and Research, 345 Cramer Hall, Portland State University, telephone 4643423 . 